\title{
An Insight Into The MicroRNA Profiles of An Ectoparasite Mite Varroa Destructor (Acari: Varroidae), The Primary Vector of Deformed Wing Virus (DWV) of The Honey Bee
}

\section{Deepak Kumar}

University of Southern Mississippi

Mohamed Alburaki

USDA ARS Bee Research Laboratory

Faizan Tahir

University of Southern Mississippi

Michael Goblirsch

USDA ARS Southern Horticultural Research Unit, Poplarville, MS, John Adamczyk

USDA ARS Southern Horticultural Research Unit, Poplarville, MS,

Shahid Karim ( $\sim$ Shahid.Karim@usm.edu )

University of Southern Mississippi

\section{Research Article}

Keywords: ectoparasite, honeybee, Varroa destructor, Deformed Wing Virus, deciphering

Posted Date: September 3rd, 2021

DOl: https://doi.org/10.21203/rs.3.rs-837468/v1

License: (c) (i) This work is licensed under a Creative Commons Attribution 4.0 International License.

Read Full License 


\section{Abstract}

The most important ectoparasite of the honeybee is the remarkably adaptive mite Varroa destructor. The Varroa mite is a competent vector of Deformed Wing Virus (DWV), the Varroa-virus complex is one of the main factors associated with elevated annual honey bee colony mortality. Micro-RNAs (miRNAs) are small, non-coding RNAs of $~ 22-24$ nucleotides, produced by all plants, animals, and viruses that influence biological processes through post-transcriptional regulation of gene expression. Knowledge of miRNAs and their functional role in mite biology remains limited. This study developed small RNA libraries from male and female $V$. destructor by utilizing Illumina's small RNA-Seq platform. A total of 101,913,208 and $91,904,732$ small RNA reads (>18 nucleotides) from male and female mites were analyzed using the mirDeep2 algorithm. A conservative approach predicted a total of 306 miRNAs, of which 18 were upregulated and 13 were downregulated in female $V$. destructor compared to males. A qPCR assay validated the expression of selected differentially expressed female Varroa miRNAs. This dataset provides a list of potential miRNA targets involved in regulating vital Varroa biological processes and for deciphering new targets against Varroa and honey bee viruses they carry.

\section{Introduction}

Varroa destructor is considered as the most damaging ectoparasite of the European honey bee (Apis mellifera) in every country it has been introduced (Hristove et al., 2020). The significance of $A$. mellifera to world food production (Gallai et al., 2009; Haung et al., 2018) and the role of $V$. destructor to honeybee colony losses make the mite one of the most significant ectoparasites (Goulson et al., 2015; Noel et al., 2020; Le Conte et al., 2010). Varroa destructorinfests honey bees by feeding on the hemolymph and fat body of pupae and adults (Ramsey et al., 2019). Varroa depletes the nutritional resources and suppresses the immune system when it feeds on its host (Yang and Cox-Foster 2005; Annoscia et al., 2019; Koleoglu et al., 2018; 2017; Di Prisco et al., 2016). The mite is a competent vector of various viral pathogens (Gisder et al., 2009; de Miranda and Genersch 2010; Wilfert et al., 2016). Varroa and associated viral pathogens have led to elevated winter losses in many regions (Highfield et al., 2009), resulting in substantial investment by beekeepers to combat infestations and replace stock. Typically, hives infested with Varroa will not survive for more than 3 years without treatment or cultural intervention (Martin 1998; von Dooremalen et al., 2012). In the United States, it has been reported that honey bee colonies would have significantly reduced chances of survival unless beekeepers use chemical treatments (Webster and Delaplane 2001; Kulhanek et al., 2021). An accurate assessment of loss caused to honey bee colonies by Varroa infestation is a technical challenge. Still, it is safe to assume that Varroa infestation has resulted in the death of thousands of honeybee colonies and losses in billions of dollars (http://entnemdept.ufl.edu/creatures/misc/bees/varroa_mite.html).

Varroa foundresses vector Deformed Wing Virus (DWV) to immature honey bees when they feed. DWV is the major cause of honeybee colony collapse. Interestingly, DWV infection is maintained naturally in honey bees and rarely pathogenic in the absence of Varroa infestation (Beaurepair et al. 2019). Contrary to low levels of infection maintenance, inoculation of DWV via Varroa feeding significantly increases the 
viral load in the pupal stage (Gusachenko et al. 2020). Bees that are symptomatic for DWV emerge with wing deformities, have reduced weight, and a shortened lifespan or are killed prematurely by other members of the colony. Bees can be asymptomatic but have high viral load that leads to negative effects on lifespan, foraging and flight capability, behavioral maturation, and immunity (Well et al., 2016; Natsopoulu et al., 2016; Pizzomo et al., 2021; Traniello et al., 2020; Benaets et al., 2017; Iqbal and Mueller 2007; Brettell et al., 2017). By feeding on honey bee pupae, Varroa acts as an efficient vector of viruses. Varroa is known to maintain and vector over a dozen viruses to their bee host. However, only DWV and Acute bee paralysis virus (ABPV) are pathogenic and vectored by Varroa (Martin and Brettell, 2019; de Miranda et al., 2013). Studies have demonstrated that DWV-load significantly increased upon Varroa infestation in the hive, and subsequently, honeybee mortality (Beaurepair et al. 2020, Gusachenko et al. 2020). These Varroa-borne viruses have several co-circulating variants that differ in their virulence (Gisder et al. 2018, Posada-Florez et al. 2019, Martin and Brettell, 2019, Remnant et al. 2019, Moore et al. 2011, Ryabov et al. 2019, Mordecai et al. 2016). Although there is clear correlation between harboring DWV by Varroa and infection to honey bees, the underlying genetic mechanisms of vector competence (acquisition, maintenance, and transmission) needs further clarification. A detailed understanding of vector competence for DWV by Varroa is required in order to develop intervention strategies to prevent Varroa infestation and Varroa-borne viral transmission to honey bees.

The control and prevention of Varroa is primarily based on chemical acaricides. The reliance on synthetic acaricides has resulted in the development of Varroa resistance (Higes et al., 2020; Rinkevich 2020). Varroa is highly efficient in vectoring honey bee viruses and plays a role in driving changes in virus distribution, prevalence, and virulence (Traynor et al. 2020). Clearly, current control strategies are not sufficient; more effective and novel approaches need to be adopted to tackle this global problem. A novel microRNA approach has been investigated in this study to find potential microRNAs (miRNAs) that regulate Varroa vector competence. MicroRNAs are single strands of non-coding RNA about 22-25 nucleotides long derived from larger hairpin RNA precursors. involved in most physiological and pathological processes through post-transcriptional regulation of several target genes. MicroRNAS are being used as therapeutic targets of several diseases (Bartel et al. 2018). In mammals, miRNAs can regulate more than $30 \%$ of protein-coding genes and most cellular processes (Filipowicz et al. 2008). Information is limited on arthropod miRNAs and their role in arthropod physiology (Lucas and Raikhel 2013; Luhur et al. 2013; He et al. 2015). In arthropods, the identification and functional role of microRNAs in various biological processes are sparse (Asgari 2014; Blair and Olson 2015; Barrero et al. 2011; Zhou et al. 2013; Luo et al. 2015; Shao et al. 2015; Wang et al. 2015). Given the importance of Varroa as a honey bee parasite and vector of honey bee viruses the availability of high-quality de-novo reference genomes of $V$. destructor and $V$. jacobsoni opened new avenues to map the non-coding small RNAs in the mite genome (Techer et al., 2019). Available literature suggests the significance of microRNAs as critical regulators of many biological processes and pathogen infection in arthropods (Feng et al. 2018). Studies have indicated a significant role of miRNAs in replicating, harboring, and inhibiting other RNA viruses such as dengue virus (DENV), chikungunya virus (CHIKV), and other viruses and intracellular pathogens in arthropods (Sempere et al. 2003, Hussain et al. 2013, Maharaj et al. 2015). Therefore, information 
about Varroa microRNAs could play a significant role in understanding how Varroa miRNAs participate in colonizing DWV and its transmission to honeybees.

Our aim was to predict the expression patterns of conserved and novel miRNAs in male and female Varroa. This study provides insight into the physiological roles of miRNAs in gene regulatory networks and their biological function in the ectoparasitic mite. Identification of novel miRNAs provide a platform for the fundamental understanding of the role of miRNAs in the transmission of Varroa-borne viruses and other biological pathways.

\section{Materials And Methods}

\section{Varroa mite collection}

Varroa were collected from A. mellifera colonies maintained at the University of Southern Mississippi's Lake Thoreau Environmental Center in Hattiesburg, MS (31 $20^{\circ} 54.476 " \mathrm{~N}$ and $89^{\circ} 25^{\prime} 9.202^{\prime \prime} \mathrm{W}$ ) during August-October, 2019. Adult female mites were collected from adult honey bee workers using the sugar shake method (Gregorc et al. 2018). Male Varroa were collected from sealed pupal cells by removing the wax cap and positively identifying males in infested cells using microscopy. A total of 10 male and 20 female Varroa were collected separately in tubes containing Trizol for RNA extraction.

\section{RNA extraction}

RNA was extracted from male and female mites separately using the TRIZOL extraction method (Chozyzynski et al. 1995) with some modifications to the original protocol. Briefly, mites were collected individually then pooled male and female mites in separate tubes. Mites were homogenized in $500 \mu \mathrm{l}$ of Trizol using a plastic pestle. After homogenization, samples were mixed for $10 \mathrm{~min}$ at room temperature in a shaker followed by centrifugation at $15000 \mathrm{xg}$ for 10 mins at $4^{\circ} \mathrm{C}$. The supernatant was transferred to a new tube and incubated for $5 \mathrm{~min}$ at room temperature to permit complete dissociation of the nucleoproteins. One hundred $\mu \mathrm{l}$ chilled chloroform was added to the samples, mixed, and incubated for 10 mins at $4^{\circ} \mathrm{C}$. Samples were centrifuged at $15000 x$ for 15 mins to obtain an aqueous phase. The aqueous phase was transferred to a new tube and then $600 \mu \mathrm{l}$ of isopropanol was added and kept overnight at $-20^{\circ} \mathrm{C}$. The following day, samples were centrifuged for 15 mins at $4^{\circ} \mathrm{C}$ followed by $70 \%$ ethanol wash of pellets. RNA pellets were dried appropriately, and RNA samples were resuspended in sterile water and quantified using Nanodrop.

\section{Small RNA Sequencing}

The RNA concentration of pooled Varroa females was $286.5 \mathrm{ng} / \mathrm{ul}(260 / 280=1.8)$ and for pooled Varroa males was $185.6 \mathrm{ng} / \mathrm{ul}(260 / 280=1.8)$. Small RNA libraries were prepared using the Illumina Truseq Kit following the manufacturer's instructions. Briefly, short adapter oligonucleotides were ligated to each end of the small RNAs in the samples. Individual CDNA copies were made with reverse transcriptase, and PCR was used to add sample-specific barcodes and Illumina sequencing adapters. The final concentration of 
all NGS libraries was determined using a Qubit fluorometric assay. The cDNA fragment size of each library was assessed using a DNA 1000 high-sensitivity chip on an Agilent 2100 Bioanalyzer. Before sequencing, samples passed the essential quality control (QC) test. After purification by polyacrylamide gel electrophoresis, the sample libraries were pooled and sequenced on an Illumina Next Seq 500 (single end 36 bases) using TruSeq SBS kit v3 (Illumina) and protocols defined by the manufacturer. Four small RNA libraries of pooled male and female Varroa mites were sequenced via Illumina small RNA highthroughput sequencing. RNA library preparation and indexing were performed by the University of Mississippi Medical Center's genomics core facility. Small RNA sequencing was performed on Illumina Next Seq 500 high output (300 cycles) as single-end sequences.

\section{Bioinformatics analysis}

The miRDeep2 software package (Friedlander et al. 2008), version 2.0.0.8, was used to process the sequencing data. For the novel miRNA prediction step, the reads from all the samples were combined. The mapper function of miRDeep2 trimmed the adapter sequences from the reads and converted the read files from fastq to fasta format. Reads shorter than 18 bases were discarded. Remaining reads were then mapped to the V.destructor reference genome (Techer et al., 2019) using the default miRDeep2 mapper function parameters. Reads that mapped to the genome were used to predict novel miRNAs. The Drosophila melanogaster genome was also provided as a reference genome and mapped reads were aligned to available microRNAs of $D$. melaongaster in miRbase (Version 22) and quantified. The output file included sequence and location of the possible miRNAs, the number of reads that mapped to it, and a score reflecting the likelihood that the predicted miRNA was not due to chance alone. The software aligned the reads to the reference genomes of $D$. melanogaster and $V$. destructor and looked for locations where potential miRNA reads accumulated. The regions immediately surrounding the mapped reads were examined for miRNA biogenesis features, including mature miRNAs, Star and precursor reads, and stemloop folding properties. Essentially, the miRDeep2 program models the miRNA biogenesis pathway, using a probabilistic algorithm to score compatibility of the position and frequency of Next-Gen Sequencing (NGS) reads with the secondary structure of the miRNA precursor. BEDtools (Quinlan and Hall, 2010) were used to determine the genomic origin of the precursors with the variant intersect.

\section{Validation of differentially expressed miRNAs by qRT-PCR}

Predicted mRNAs that were differentially expressed in small RNA sequencing were validated by qRT-PCR. RNA samples from male and female Varroa were converted to cDNA, and the miRNA-specific qRT-PCR reaction was performed for each sample. Mir-X miRNA qRT-PCR TB Green kit from Takara BIO (catalog \# 638316) was used for cDNA synthesis and miRNA expression analysis. Conditions used for qRT-PCR were initial denaturation $95^{\circ} \mathrm{C}$ for 10 mins, then 40 cycles of $95^{\circ} \mathrm{C}$ for 5 secs, $60^{\circ} \mathrm{C}$ for 20 secs.

\section{Normalization, Differential expression (DE) and Statistical analysis of miRNA expression between male and female Varroa mites}


In silico differential expression analysis of predicted miRNAs were performed using the interactive web interface DeApp (Li and Andrade, 2017). DeApp is a web-based, graphical interface developed in $\mathrm{R}$ with the shiny package (web application framework for R). Low expression genetic features were removed after alignment if the counts per million (CPM) value was $\leq 1$ in less than two samples. Normalization of samples and a multidimensional scaling (MDS) plot have been provided as supplementary data (Fig. S2) and includes details about sample distribution after filtering out the low expression genomic features. Differential expression (DE) analysis was performed by edgeR, the false discovery rate (FDR) adjusted $p$ value was set at 0.05 , and minimum fold change was set at 1.5 . In the end, this interface displays a dispersion plot showing the results of overall DE analysis along with statistical significance ( $p$-value, FDR adjusted $p$-value, Table 1) with a volcano plot (Fig. 3A) corresponding to the specified parameters and cutoff values. 
Table 1

In silico differential expression analysis of whole body female Varroa mite microRNAs relative to male microRNAs. miRNAs with a Log2 fold-change expression $>|1|$ and FDR $\leq 0.1$ were considered significantly differentially expressed with respect to male microRNAs.

\begin{tabular}{|c|c|c|c|c|c|}
\hline Predicted miRNA & $\log 2 \mathrm{FC}$ & $\log C P M$ & LR & P-value & FDR \\
\hline vde-miR-1002-5p & -4.511 & 13.92626 & 108.6748 & $1.9 \mathrm{E}-25$ & $5.8 \mathrm{E}-24$ \\
\hline vde-miR-263b-5p & -4.27 & 11.69984 & 13.43531 & 0.00025 & 0.00125 \\
\hline novel:nDS_019211454.1_2946 & -3.814 & 11.56138 & 9.607184 & 0.00194 & 0.0084 \\
\hline novel:nDS_019211458.1_34062 & -2.671 & 11.8175 & 10.05673 & 0.00937 & 0.03157 \\
\hline novel:nDS_019211458.1_36783 & -2.671 & 11.69432 & 6.75152 & 0.00937 & 0.03157 \\
\hline novel:nDS_019211455.1_15579 & -2.639 & 11.69432 & 6.75152 & 0.04995 & 0.11365 \\
\hline novel:nDS_019211454.1_3258 & -2.639 & 11.87389 & 7.292297 & 0.04995 & 0.11365 \\
\hline novel:nDS_019211460.1_42775 & -2.639 & 13.6527 & 33.64388 & 0.04995 & 0.11365 \\
\hline novel:nDS_019211454.1_3053 & -2.639 & 13.59985 & 9.317998 & 0.04995 & 0.11365 \\
\hline novel:nDS_019211454.1_7299 & -2.37 & 13.59696 & 6.516879 & 0.00693 & 0.02524 \\
\hline novel:nDS_019211455.1_16072 & -2.079 & 16.93765 & 27.64951 & $6.6 \mathrm{E}-09$ & $8.6 \mathrm{E}-08$ \\
\hline novel:nDS_019211456.1_22220 & -1.586 & 17.49914 & 65.70939 & 0.00049 & 0.00236 \\
\hline vde-miR-958-3p & -0.714 & 15.89762 & 12.14634 & $1.5 \mathrm{E}-07$ & $1.5 \mathrm{E}-06$ \\
\hline vde-miR-34-5p & 1.544 & 14.39795 & 8.821865 & 5.7E-05 & 0.00033 \\
\hline vde-miR-278-3p & 1.616 & 13.43659 & 5.955626 & 0.00693 & 0.02524 \\
\hline vde-bantam-3p & 1.678 & 13.71432 & 16.20957 & $5.2 \mathrm{E}-16$ & $7.9 \mathrm{E}-15$ \\
\hline vde-miR-4968-5p & 1.844 & 12.6881 & 7.289986 & $4.5 \mathrm{E}-23$ & $1 \mathrm{E}-21$ \\
\hline vde-miR-6-3p & 2.249 & 15.67949 & 97.85967 & 1.3E-06 & $9.5 \mathrm{E}-06$ \\
\hline vde-miR-4943-3p & 2.781 & 13.41013 & 23.49429 & $4 \mathrm{E}-07$ & 3.7E-06 \\
\hline novel:nDS_019211454.1_6280 & 2.903 & 13.71203 & 30.86426 & 0.04952 & 0.11365 \\
\hline novel:nDS_019211454.1_3169 & 3.035 & 13.19444 & 25.68681 & 3.6E-05 & 0.00024 \\
\hline vde-miR-87-3p & 3.064 & 12.65187 & 16.14825 & 0.00152 & 0.00691 \\
\hline novel:nDS_019211455.1_9027 & 3.186 & 12.73314 & 17.05458 & 0.0281 & 0.07748 \\
\hline vde-miR-313-5p & 3.276 & 12.38077 & 14.03693 & 0.00018 & 0.00096 \\
\hline novel:nDS_019211459.1_37129 & 3.422 & 11.60818 & 5.786587 & 0.01615 & 0.0474 \\
\hline novel:nDS_019211459.1_37910 & 3.422 & 11.60899 & 5.786596 & 0.01615 & 0.0474 \\
\hline
\end{tabular}




\begin{tabular}{|llllll|}
\hline Predicted miRNA & log2FC & logCPM & LR & P-value & FDR \\
\hline vde-miR-92a-3p & 3.915 & 12.76538 & 23.93004 & $1 \mathrm{E}-06$ & $8.3 \mathrm{E}-06$ \\
\hline novel:nDS_019211454.1_5540 & 4.923 & 14.12569 & 93.45913 & $4.1 \mathrm{E}-22$ & $7.5 \mathrm{E}-21$ \\
\hline vde-miR-9a-3p & 5.062 & 12.30162 & 19.28666 & $1.1 \mathrm{E}-05$ & $7.9 \mathrm{E}-05$ \\
\hline vde-miR-375-3p & 7.668 & 14.18509 & 114.5216 & $1 \mathrm{E}-26$ & $4.6 \mathrm{E}-25$ \\
\hline novel:nDS_019211456.1_17707 & 9.727 & 16.02422 & 433.5094 & $2.8 \mathrm{E}-96$ & $2.5 \mathrm{E}-94$ \\
\hline
\end{tabular}

\section{Prediction of the target genes, Proteome re-annotation, Gene Ontology (GO) and KEGG enrichment analyses}

The targeting algorithmsTargetSpy (Sturm et al. 2010), MIRANDA (John et al. 2004), and PITA (Kertesz et al. 2007) were used in miRNAcons Target from sRNAtoolbox to predict the genes regulated by the Varroa miRNAs which were found either up- or downregulated via in silico analysis (Fig. 3A-B) (Aparicio-Puerta et al., 2019). Targets common in all three programs were further considered. In silico target prediction provided a high number of false positives, but cross-species comparisons and combinatorial effects led to a reduction in this number (Min and Yoon, 2010). Lists of target genes were functionally characterized using the STRING webserver (Franceschini et al. 2013). The networks of target genes and the KEGG pathways significantly enriched for target genes were extracted using the STRING output (Table 3). PANNZER2 (Toronen et al., 2018) was used to functionally re-annotate the predicted proteome of up- or downregulated genes (targets of predicted miRNAs), and WEGO (Ye et al., 2018) was used to analyze and plot gene ontology (GO) annotations.

\section{Results}

\section{Read length distribution of small RNAs}

After adapter trimming and removal of short reads ( $\leq 18$ nucleotides), 101,914,732 small RNA reads were available for the Varroa males, and 91, 904, 732 for females to conduct downstream analysis. Among available sequences from male Varroa, 27,204,163 were matched to the Varroa genome, whereas $32,283,353$ female reads matched to the genome. The read length distribution provides the types of small RNA present in male and female Varroa samples. Figure 1 depicts the number of short-read sequences in the range of 18-30 nucleotides. Three main peaks were distinguishable in both male and female samples: i) a peak of 24 nucleotides, the highest abundant population of mature microRNA and, ii) peaks of 22 and iii) 23 nucleotides, relatively less abundant than that of 24 nucleotide microRNAs. The number of 24 nucleotide microRNA sequences was $\sim 2.2 \times 10^{7}$ and $\sim 1.8 \times 10^{7}$ in male and female Varroa. The number of 22 and 23 nucleotide small RNA sequences was $\sim 1.25 \times 10^{7}$ and $\sim 1.8 \times 10^{7}$ for male, and $\sim$ $1.0 \times 10^{7}$ and $\sim 1.7 \times 10^{7}$ for female samples, respectively. The read length distribution in male Varroa was found to be qualitatively identical to females. 


\section{The miRNA profiles of Varroa}

Fig. 2A shows the basic hair-pin-loop structure of a microRNA and other parameters (dicer cut overhangs, total read count, mature read count, loop read count, total read count, randfold score, and total score) used to determine whether a hair-pin-loop structured RNA is a microRNA. In this study, a total of 306 microRNAs were predicted in $V$. destructor, and several had homologs present in $D$. melanogaster. The predicted miRNAs were categorized as high $(n=50)$ and low confidence $(n=80)$ (Fig. 2B, Table S1) based on standard criteria (Bartel et al., 2018). Eighteen of the predicted miRNAs were upregulated, whereas 13 were downregulated in female Varroa compared to male Varroa (Fig. 3A-B; Table 1). Four of the predicted mature microRNAs, nDS_019211455.1_10989, nDS_019211455.1_7097, nDS_019211459.1_37116 and, nDS_019211459.1_24860 were detected in female but not male Varroa, and two of the predicted miRNAs, nDS_019211455.1_10989 and nDS_019211455.1_16072 were detected in male but not female Varroa. Supplementary data (Table S1) includes the consensus mature, star, the total read counts, and the miRDeep2 score and probability for every miRDeep2-predicted miRNA with a miRDeep2 score.

\section{In silico differential expression (DE) analysis of miRNAs predicted in the Varroa mites}

In silico analysis predicted a total of 306 microRNAs; fifty were of high confidence, and eighty were of low confidence (Fig. 2, Table S1). Eighteen of the predicted microRNAs were upregulated, while 13 of them were down-regulated in females compared to male Varroa (Fig. 3-4 and Table 1).

\section{Differential expression analysis by qRT-PCR}

Several of the predicted Varroa miRNAs were found conserved in D. melanogaster. Earlier studies showed their conserved roles in development, replication, viral colonization, and viral inhibition in other arthropods (Fig. 4A, Table 2). The qRT-PCR expression of these high-confidence predicted miRNAs such as vde-miR87-3p, vde-bantam-3p, vde-miR-375-3p, and vde-miR-34-5p were upregulated 100 to 20,000-fold in DWVinfected female relative to male Varroa (Fig. 4B). 
Table 2

List of potential microRNA candidates predicted in this study, conserved in Drosophila melanogaster (Dm) also and based on the available literature, play a significant role in development, replication, harboring and inhibition of viral pathogens

\begin{tabular}{|c|c|c|c|c|c|}
\hline $\begin{array}{l}\text { Predicted } \\
\text { microRNA }\end{array}$ & Annotation & $\begin{array}{l}\text { Dm } \\
\text { homologs }\end{array}$ & $\begin{array}{l}\text { Role of microRNA (from } \\
\text { literature) }\end{array}$ & $\begin{array}{l}\text { Target } \\
\text { genes }\end{array}$ & Reference \\
\hline $\begin{array}{l}\text { vde-miR- } \\
278-3 p\end{array}$ & $\begin{array}{l}\text { High } \\
\text { Confidence }\end{array}$ & $\begin{array}{l}\text { dme-miR- } \\
278-3 p\end{array}$ & $\begin{array}{l}\text { Insecticide pyrethroid } \\
\text { resistance }\end{array}$ & CYP6AG11 & $\begin{array}{l}\text { Lei et al. } \\
2015\end{array}$ \\
\hline $\begin{array}{l}\text { vde-miR-6- } \\
3 p\end{array}$ & $\begin{array}{l}\text { High } \\
\text { Confidence }\end{array}$ & $\begin{array}{l}\text { dme-miR- } \\
6-3 p\end{array}$ & Metamorphosis & & $\begin{array}{l}\text { Sempere } \\
\text { et al. } \\
2003\end{array}$ \\
\hline $\begin{array}{l}\text { vde-miR- } \\
9 a-3 p\end{array}$ & $\begin{array}{l}\text { High } \\
\text { Confidence }\end{array}$ & $\begin{array}{l}\text { dme-miR- } \\
9 a-3 p\end{array}$ & In developmental stages & & \\
\hline $\begin{array}{l}\text { vde-miR- } \\
375-3 p\end{array}$ & $\begin{array}{l}\text { High } \\
\text { Confidence }\end{array}$ & $\begin{array}{l}\text { dme-miR- } \\
375-3 p\end{array}$ & $\begin{array}{l}\text { Dengue virus (DENV) } \\
\text { replication in mosquitoes }\end{array}$ & $\begin{array}{l}\text { Cactus, } \\
\text { REL1 }\end{array}$ & $\begin{array}{l}\text { Hussain } \\
\text { et al. } \\
2013\end{array}$ \\
\hline $\begin{array}{l}\text { vde-miR- } \\
34-5 p\end{array}$ & $\begin{array}{l}\text { High } \\
\text { Confidence }\end{array}$ & $\begin{array}{l}\text { dme-miR- } \\
34-5 p\end{array}$ & $\begin{array}{l}\text { Immune response during } \\
\text { DENV-2 infection }\end{array}$ & & $\begin{array}{l}\text { Liu et al. } \\
2015\end{array}$ \\
\hline $\begin{array}{l}\text { vde-miR- } \\
252-5 p\end{array}$ & $\begin{array}{l}\text { High } \\
\text { Confidence }\end{array}$ & $\begin{array}{l}\text { dme-miR- } \\
252-5 p\end{array}$ & Inhibits DENV replication & & $\begin{array}{l}\text { Yan et al. } \\
2014\end{array}$ \\
\hline $\begin{array}{l}\text { vde- } \\
\text { bantam-3p }\end{array}$ & $\begin{array}{l}\text { High } \\
\text { Confidence }\end{array}$ & $\begin{array}{l}\text { dme- } \\
\text { bantam- } \\
3 p\end{array}$ & $\begin{array}{l}\text { Proliferation, development, } \\
\text { apoptosis, CHIKV infection }\end{array}$ & & $\begin{array}{l}\text { Maharaj } \\
\text { et al. } \\
2015\end{array}$ \\
\hline $\begin{array}{l}\text { vde-miR-8- } \\
3 p\end{array}$ & $\begin{array}{l}\text { High } \\
\text { Confidence }\end{array}$ & $\begin{array}{l}\text { dme-miR- } \\
8-3 p\end{array}$ & A. aegypti reproduction & SWIM & $\begin{array}{l}\text { Lucas et } \\
\text { al. } 2015\end{array}$ \\
\hline $\begin{array}{l}\text { vde-miR- } \\
87-3 p\end{array}$ & $\begin{array}{l}\text { High } \\
\text { Confidence }\end{array}$ & $\begin{array}{l}\text { dme-miR- } \\
87-3 p\end{array}$ & $\begin{array}{l}\text { Metamorphosis, Immune } \\
\text { response during DENV-2 } \\
\text { infection }\end{array}$ & & $\begin{array}{l}\text { Sempere } \\
\text { et al. } \\
2003\end{array}$ \\
\hline
\end{tabular}

\section{Other small RNA categories}

A summary of reads that match various small RNA categories from both male and female Varroa are shown in Fig. 5. Other small RNAs include signal recognition particle (SRP), protein-coding, and not annotated RNAs. Out of the total small RNA reads of female Varroa, $56 \times 10^{-4} \%$ were miRNA, $15 \times 10^{-2}$ were rRNA, $5 \times 10^{-1}$ were tRNA, $13 \times 10^{-4}$ were snRNA, $29 \times 10^{-5}$ were snoRNA, and $99.35 \%$ were others. Among total reads of small RNA of male Varroa, $25 \times 10^{-4} \%$ were covered by miRNA, $15 \times 10^{-3}$ by rRNA, $94 \times 10^{-3}$ by tRNA, $4 \times 10^{-4}$ by snRNA, $2.35 \times 10^{-5}$ by snoRNA, and $99.89 \%$ by others.

\section{Prediction of target genes and gene ontology (GO) and functional enrichment analyses in the target network}

The STRING web analysis (Fig. 6A) showed that target proteins for 31 predicted miRNAs (18 upregulated and 13 downregulated) have more interactions than what would be expected for a random set of proteins 
of similar size sampled from the $V$. destructor genome (number of nodes $=42$, number of edges $=97$, average node degree $=4.62$, average local clustering coefficient $=0.476$, expected number of edges $=25$, PPI enrichment $p$-value $<1.0 \mathrm{e}-16)$. Such enrichment indicates that the proteins are at least partially biologically connected as a group. To minimize the number of false-positive targets, we opted only for those targets which were predicted by all three miRNA target programs (TargetSpy, MIRANDA, and PITA). The predicted miRNAs are of high confidence, and the main KEGG pathways involved were predicted as oxidative phosphorylation (12 out of 80 ), endocytosis (4 out of 116), protein processing in the endoplasmic reticulum (2 out of 109), and other metabolic pathways (14 out of 810). Many target genes were predicted for the differentially expressed miRNAs in the small RNA-Seq data (Fig. 6B) using the miRNAconsTarget program from sRNAtoolbox (Aparicio-Puerta et al., 2019).

Genes controlled by the conserved miRNAs (D. melanogaster, V. destructor) identified in this study regulate development, metamorphosis, proliferation, apoptosis, reproduction (Aedes aegypti), insecticide resistance and also antiviral immune responses (Table 2). Interestingly, analysis of $\mathrm{GO}$ terms related to genes regulated by the shared miRNAs revealed many specific processes known to be regulated by the same miRNAs in D. melanogaster, such as developmental processes, metamorphosis, immune response which reinforces its conservative role (Fig. 7; Table 2).

\section{Validation of predicted microRNAs of female Varroa by qRT-PCR}

The expression of 13 predicted differentially expressed miRNAs were validated using qRT-PCR assay (Fig. 8). The qRT-PCR patterns of differentially expressed microRNAs matched the NGS patterns in the majority of evaluated miRNAs. Inconsistencies in the patterns of NGS data and qRT-PCR data were found for nDS_0192211459.1_37129, nDS-miR-6-3p, nDS-miR-4943-3p, nDS_019211456.1_17707, and nDS_019211457.1_26197. These differences could be due to different methodologies of quantifying miRNA expression (Saldana et al., 2017).

Table 3 - Functional enrichment in predicted protein network (STRING) 


\begin{tabular}{|c|c|c|c|c|}
\hline$\checkmark$ & local network cluster (STRING) & & & \\
\hline cluster & description & count in network & strength & false discovery rate \\
\hline CL-6542 & mixed, incl. Zinc-finger domain, and ETC complex I subunit conse_ & 6 of 8 & 2.57 & $1.90 \mathrm{e}-12$ \\
\hline CL-6638 & Oxidative phosphorylation & 8 of 13 & 2.48 & $7.16 \mathrm{e}-16$ \\
\hline CL-6668 & mixed, incl. Translocase, and $4 \mathrm{Fe} \cdot 4 \mathrm{~S}$ binding domain & 3 of 6 & 2.39 & $8.24 \mathrm{e} \cdot 06$ \\
\hline CL-6536 & Oxidative phosphorylation & 11 of 25 & 2.34 & $3.76 \mathrm{e} \cdot 20$ \\
\hline CL-6630 & Oxidative phosphorylation, and Porin, eukaryotic type & 12 of 67 & 1.95 & $2.16 \mathrm{e}-18$ \\
\hline $\mathrm{CL}-8320$ & mixed, incl. Protein transport, and Pleckstrin homology domain. & 3 of 148 & 1.0 & 0.0383 \\
\hline
\end{tabular}

\begin{tabular}{|c|c|c|c|c|}
\hline \multicolumn{5}{|c|}{ KEGG Pathways } \\
\hline tut00190 & Oxidative phosphorylation & 10 of 80 & 1.79 & $1.11 \mathrm{e}-14$ \\
\hline tut01100 & Metabolic pathways & 12 of 810 & 0.86 & $1.46 \mathrm{e} \cdot 07$ \\
\hline
\end{tabular}

\begin{tabular}{|c|c|c|c|c|}
\hline & Annotated Keywords (UniProt) & & & \\
\hline keyword & description & count in network & strength & false discovery rate \\
\hline KW.0342 & GTP-binding & 3 of 74 & 1.3 & 0.0197 \\
\hline KW-0813 & Transport & 5 of 358 & 0.84 & 0.0197 \\
\hline
\end{tabular}

\begin{tabular}{|c|c|c|c|c|}
\hline$\checkmark$ & Protein Domains (Pfam) & & & \\
\hline domain & description & count in network & strength & false discovery rate \\
\hline PF05347 & Complex 1 protein (LYR family) & 2 of 6 & 2.22 & 0.0070 \\
\hline PF00350 & Dynamin family & 2 of 8 & 2.09 & 0.0070 \\
\hline PF00153 & Mitochondrial carrier protein & 2 of 40 & 1.39 & 0.0343 \\
\hline PF00520 & Ion transport protein & 2 of 43 & 1.36 & 0.0343 \\
\hline PF08477 & Ras of Complex, Roc, domain of DAPkinase & 3 of 71 & 1.32 & 0.0091 \\
\hline PF00025 & ADP-ribosylation factor family & 3 of 70 & 1.32 & 0.0091 \\
\hline PF00071 & Ras family & 3 of 79 & 1.27 & 0.0091 \\
\hline
\end{tabular}

\begin{tabular}{|c|c|c|c|c|}
\hline$\checkmark$ & Protein Domains and Features (InterPro) & & & \\
\hline IPR030381 & Dynamin type guanine nucleotide-binding (G) domain & 2 of 5 & 2.29 & 0.0098 \\
\hline IPR022812 & Dynamin superfamily & 2 of 7 & 2.15 & 0.0098 \\
\hline IPR020849 & Small GTPase superfamily, Ras-type & 2 of 18 & 1.74 & 0.0145 \\
\hline IPR002067 & Mitochondrial carrier protein & 2 of 18 & 1.74 & 0.0145 \\
\hline IPR018108 & Mitochondrial substrate/solute carrier & 2 of 36 & 1.44 & 0.0314 \\
\hline IPR001806 & Small GTPase & 3 of 60 & 1.39 & 0.0098 \\
\hline IPR005225 & Small GTP.binding protein domain & 3 of 79 & 1.27 & 0.0142 \\
\hline \multirow[t]{2}{*}{ IPR027417 } & P-loop containing nucleoside triphosphate hydrolase & 6 of 557 & 0.72 & 0.0145 \\
\hline & & & & (less ...) \\
\hline
\end{tabular}

\section{Discussion}

Micro RNAs are indispensable post-transcriptional regulators of gene expression involving various biological pathways, including cell growth, apoptosis, metamorphosis, development, and vector competence (Kloosterman and Plasterk 2006). However, little is known about the expression of miRNAs in parasitic mites such as $V$. destructor. Therefore, identifying and understanding the expression profiles of miRNAs in male and female Varroa will expand our fundamental knowledge of mite miRNAs and 
provide insight into the development and vector competence of Varroa. A conservative in silico approach identified 306 microRNAs, among which 80 were of low confidence and 50 of high confidence. Among these high confidence microRNAs 18 were up- and 13 were down regulated in female compared to male Varroa. Our qRT-PCR assay confirmed the up-regulation of Varroa miRNAs such as vde-miR-87-3p, vdebantam-3p, vde-miR-375-3p, and vde-miR-34-5p, which have known roles in DENV replication, CHIKV infection, and immune response during DENV-2 infection in mosquitoes (Hussain et al. 2013; Liu et al., 2013; Yan et al., 2014; Maharaj et al., 2015; Lucas et al., 2015; Sempere et al., 2003). This small RNA dataset provides a new resource to characterize the function of miRNAs in mite biology. Other Varroa microRNAs predicted have also shown roles in development, pesticide resistance, metamorphosis, immune response, and reproduction (Fig. 4A, Table 2) in other arthropods. The new and novel microRNAs predicted in this study remain to be characterized using miRNA inhibitory assays.

Several of the predicted miRNAs identified in this study are also conserved in D. melanogaster (i.e. the assessed species along with $V$. destructor in this study) such as let-7-5p, bantam-3p, miR-8-3p, miR-34-5p, miR-263a-5p, miR-87-3p, miR-252-5p, miR-12-5p, miR-375-3p, miR-9a-3p, miR-306-5p, miR-133-3p, miR-6$3 p$, miR-276-a-3p, miR-1002-5p, miR-304-5p, and are known as having conserved roles in other arthropods as well. The bantam-3p targets the proapoptotic gene hid and is involved in several cellular processes such as cell proliferation, apoptosis, development, and the circadian clock (Brennecke et al., 2003; Kadener et al., 2009). In Aedes aegypti, bantam-3p is significantly up-regulated during pupal developmental, and the highest expression has been reported at the mid-pupal period (Bryant et al.,2010). In another study, it was most abundantly expressed in both pupal and adult male and female mosquitoes, indicating its functional importance (Feng et al., 2018) and its role in Varroa development.

Another conserved miRNA miR-8-3p is significantly up-regulated in Aedes aegypti during pupation and has the highest expression at the mid-pupal period. The miR-8-3p is also significantly up-regulated in the fat body. Bryant et al., (2010) showed the up-regulation of miR-8-3p in the fat body of a blood-fed female mosquito and suggested a potential regulatory role in Ae. aegypti reproduction. Contrary to Ae. aegypti, miR-8-3p is abundantly expressed in Anopheles stephensi developmental stages (Feng et al., 2018) and found to be equally expressed in uninfected or infected Aedes albopictus saliva upon infection by CHIKV (Maharaj et al., 2015). In Ae. aegypti, miR-8 has been validated to target SWIM (secreted winglessinteracting molecule), thereby regulating reproductive events (Lucas et al.,2015). Additionally, miR-8 shows cell-type specificity and is expressed in S2 cells (a cell line derived from Drosophila melanogaster embryos). Its temporal expression is less restricted in Drosophila, and has been observed across all developmental stages occasionally with significant variation in expression (Jin et al., 2012). On the basis of above-mentioned studies, the conserved nature of miR-8-3p also indicates its possible role in Varroa development, reproduction, and virus infection and requires further investigation. Another miRNA predicted in this study that is common to Drosophila is miR-34-5p, which is more pronounced in female midguts in Anopheles gambiae (Winter et al., 2007). In contrast, it is down-regulated in Drosophila during the metamorphosis period (pupa to adult stage transition) (Sempere et al., 2003). Interestingly, in Anopheles gambiae, miR-34-5p expression was found down-regulated in the midgut upon Plasmodium falciparum infection (Dennison et al., 2015). The miR-34-5p is suggested to contribute to anti-pathogen 
and immune responses during DENV-2 infection in Ae. albopictus (Liu et al., 2015). Conserved nature of this microRNA indicates its possible role towards development regulation in Varroa but requires further studies. Our in silico data showed upregulation, and our qRT-PCR data has shown its upregulation by 5000 fold in DWV-B infected varroa females suggesting its possible role in anti-DWV-B and immune response during DWV-B infection, or it might have contribution towards DWV-B survival inside Varroa which requires further work to dissect it. In our insilico study, miR-87-3p was found upregulated in female Varroa. Previous studies have suggested its role in development in Drosophila (Sempere et al. 2003), and anti-viral, immune responses during DENV-2 infection in Ae. albopictus (Liu et al., 2015). Our qRT-PCR analysis has also demonstrated its high expression of $~ 300$ folds in DWV-B infected Varroa females suggesting its possible role either in anti-DWV-B immune response or in harboring DWV-B subject to further investigation. Another microRNA surfaced in our data is miR-375-3p. In Ae. aegypti, miR-375-3p is expressed in the blood-fed mosquitoes. miR-375 was found as the key to dengue virus (DENV) replication, enhancing DENV-2 infection in an Ae.aegypti cell line (Hussain et al., 2013). Ae. aegypti miR-375 targets Cactus, and REL 1 genes, and the injection of a miRNA mimic into mosquitoes led to fold-changes in immune gene transcripts, suggesting that aae-miR-375 enhanced DENV-2 infection (Hussain et al., 2013). It enhances Dengue virus serotype-2 infection in Ae. aegypti. Our qRT-PCR data has also shown its 20,000 fold upregulation in DWV-B infected Varroa suggesting its possible role in DWV-B infection. Interestingly, the expression of miR-263a-5p in uninfected and CHIKV-infected Ae. aegypti saliva was upregulated considerably (Maharaj et al., 2015). The miR263a-5p is constitutively expressed across many developmental stages in several mosquito species (Hu et al., 2015). Another conserved dme-miR-252-5p was induced more than three-fold after DENV-2 infection in an Ae. albopictus C6/36 cell line and inhibited DENV replication by suppressing the expression of the DENV envelope protein. It has been validated to target DENV-2 envelope gene in Ae. albopictus, thereby regulating expression of DENV-2 E protein (Yan et al., 2014). In An. gambiae, dme-miR-12-5p is shown in the thorax of males and females, predominantly in midguts, and in their heads considerably constitutively expressed (Winter et al., 2007). The dme-miR-12$5 p$ targets DNA replication licensing factor (MCM6) and monocarboxylate transporter (MCT1) genes, as validated in Ae. aegypti, by which it affects Wolbachia density in host cells (Osei-Amo et al., 2012). The dme-mir-279-3p is expressed evenly and ubiquitously throughout the An. gambiae body (Winter et al., 2007). Another conserved miRNA predicted in this study is dme-miR-278-3p, and it is highly and abundantly expressed miRNA in the reported research (Feng et al., 2018). It was up-regulated in the susceptible Culex pipiens pallens strain upon pyrethroid exposure; a widely and indiscriminately used insecticide. The miR-278-3p targets CYP6AG11 in Culex pipiens pallens to regulate Pyrethroid resistance (Lei et al., 2015). The pyrethroid tau-fluvalinate (Apistan ${ }^{\circledR}$ ) is among the first synthetic varroacides registered in the United States, and Varroa resistant to pyrethroid is a big problem in controlling this mite. Varroa resistant to pyrethroid is associated to point mutations in the gene voltage-gated sodium channel gene at position 925 (Millan-Leiva et al., 2021). Further dissection of mechanism of miR-278-3p and pyrethroid resistance along with voltage-gated sodium channel gene might provide some cue towards negating pyrethroid resistance in Varroa. 
The predicted miRNAs in the Varroa small RNA-seq provide a list of conserved miRNA targets involved in regulating key biological processes. As discussed earlier, conserved Drosophila homolog microRNAs predicted in the Varroa (Fig. 4A, Table 2), including vde-miR-87-3p, vde-bantam-3p, vde-miR-375-3p and, vde-miR-34-5p. These miRNAs have been shown to play a role in inhibiting or replicating dengue (DENV) and chikungunya virus (CHIKV) in mosquito species (Sempere et al., 2003, Maharaj et al., 2015, Hussain et al., 2013). The expressions of these miRNAs were significantly up-regulated ( $100-20,000$ fold) in DWV-B infected Varroa female mites (Fig. 4B). These results indicate a functional role of these miRNAs in virus load and warrant a detailed study to characterize these miRNAs in Varroa-borne virus transmission studies.

Some of the predicted mature microRNAs such as nDS_019211455.1_10989, nDS_019211455.1_7097, nDS_019211459.1_37116 and, nDS_019211459.1_24860 were female specific, detected only in the Varroa females but not in males, and 2 of the predicted miRNAs, nDS_019211455.1_10989 and nDS_019211455.1_16072 were male-specific, detected in males but not in females. These male and female-specific microRNAs in Varroa need to be dissected on the basis of their functional roles. A previous study in a nematode Ascaris suum has predicted the role of gender specific miRNAs as a set of elongation factors, heat shock proteins, and growth factors essential for the development of the organism (Xu et al., 2012). Moreover, sperm proteins and sperm cell motility proteins were found as the targets of the male-specific miRNAs while ovarian message proteins were found as targets of femalespecific miRNAs (Xu et al., 2012).

In this study, the size distributions of miRNAs in the Varroa male and female data sets established two peaks, with a predominant peak correlated to miRNAs of 24 nucleotides in size, consistent with genomewide identification of miRNA study of the Varroa (Fonseca et al., 2021). These miRNAs are major contributors to the total small RNAs from the Varroa males and females. Moreover, it has been suggested that miRNA might be actively involved in the vector competence of the Varroa-borne viruses.

Using publicly available Varroa destructor genome data, we annotated and evaluated possible targets and infer functions of those female Varroa putative miRNAs which showed in silico up-regulation or down-regulation relative to male. The most conserved miRNAs are involved in several biological, cellular, and development processes.

Main KEGG pathways predicted by STRING web analysis were oxidative phosphorylation, endocytosis, protein processing in the endoplasmic reticulum (ER), and other metabolic pathways. In the predicted KEGG pathways, 14 proteins out of 810 have been annotated for metabolic pathways, 12 out of 80 for oxidative phosphorylation, 4 out of 116 for endocytosis, and 2 out of 109 for protein processing in the endoplasmic reticulum (Table 3). Not surprisingly, this data suggests the significance of these biological processes. Proteins involved in endocytosis and protein processing in ER could provide significant clues towards viral infection (Wang et al., 2013; Rosche et al., 2021) process in Varroa.

\section{Conclusion}


This study provides several potential miRNA targets that might play a role in regulating DWV-infection, varroa development, and physiology, although it requires further investigation by miRNA inhibitory experiments. Characterization of the Varroa microRNAs would contribute tremendously to understanding the varroa biology and survival cues of DWV inside Varroa.

\section{Declarations}

\section{Acknowledgments:}

This research was funded by USDA ARS cooperative agreement; the Mississippi INBRE (an institutional Award (IDeA) from the National Institute of General Medical Sciences of the National Institutes of Health under award P20GM103476).

This article reports the results of research only. Mention of a proprietary product does not constitute an endorsement or a recommendation by the USDA for its use. The USDA is an equal opportunity provider and employer.

\section{Competing interests}

The authors declare that they have no competing interests.

\section{Author contributions}

Conceptualization: Deepak Kumar, Shahid Karim

Data curation: Deepak Kumar

Formal analysis: Deepak Kumar

Funding acquisition: Shahid Karim, John Adamczyk

Investigation: Deepak Kumar, Mohamed Alburaki, Faizan Tahir, Michael Goblirsch, John Adamczyk, Shahid Karim

Methodology: Deepak Kumar, Shahid Karim

Project administration: Shahid Karim

Resources: John Adamczyk, Shahid Karim

Supervision; Shahid Karim

Validation: Deepak Kumar, Shahid Karim

Visualization: Deepak Kumar 
Writing, original draft: Deepak Kumar, Shahid Karim

Writing, review \& editing: Deepak Kumar, Mohamad Alburaki, Michael Goblirsch, John Adamczyk, Shahid Karim

\section{References}

1. Annoscia D, Brown SP, Di Prisco G, De Paoli E, Del Fabbro S, Frizzera D, Zanni V, Galbraith DA, Caprio E, Grozinger CM, Pennacchio F, Nazzi F.Proc Biol Sci. 2019 Apr 24;286(1901):20190331. doi: 10.1098/rspb.2019.0331

2. Aparicio-Puerta, E., Lebrón, R., Rueda, A., Gómez-Martín, C., Giannoukakos, S., Jaspez, D., Medina, J. M., Zubkovic, A., Jurak, I., Fromm, B., Marchal, J. A., Oliver, J., \& Hackenberg, M. (2019). sRNAbench and sRNAtoolbox 2019: intuitive fast small RNA profiling and differential expression. Nucleic acids research, 47(W1), W530-W535. https://doi.org/10.1093/nar/gkz415

3. Asgari S. Role of microRNAs in arbovirus/vector interactions. Viruses. 2014;6(9):3514-3534. Published 2014 Sep 23. doi:10.3390/v6093514

4. Barrero, R.A., Keeble-Gagnère, G., Zhang, B. et al. Evolutionary conserved microRNAs are ubiquitously expressed compared to tick-specific miRNAs in the cattle tick Rhipicephalus (Boophilus) microplus. BMC Genomics 12, 328 (2011). https://doi.org/10.1186/1471-2164-12-328

5. Beaurepaire AL, Ellis JD, Krieger KJ, Moritz RFA. Association of Varroa destructor females in multiply infested cells of the honeybee Apis mellifera. Insect Sci. 2019;26(1):128-134. doi:10.1111/17447917.12529

6. Behura SK. Insect microRNAs: Structure, function and evolution. Insect Biochem Mol Biol. 2007;37(1):3-9. doi:10.1016/j.ibmb.2006.10.006

7. Benaets K, Van Geystelen A, Cardoen D, De Smet L, de Graaf DC, Schoofs L, Larmuseau MH, Brettell LE, Martin SJ, Wenseleers T. Proc Biol Sci. 2017 Feb 8;284(1848):20162149. doi:

10.1098/rspb.2016.2149.

8. Brettell LE, Mordecai GJ, Schroeder DC, et al. A Comparison of Deformed Wing Virus in Deformed and Asymptomatic Honey Bees. Insects. 2017;8(1):28. Published 2017 Mar 7. doi:10.3390/insects 8010028

9. Blair CD, Olson KE. The role of RNA interference (RNAi) in arbovirus-vector interactions. Viruses. 2015;7(2):820-843. Published 2015 Feb 17. doi:10.3390/v7020820

10. Brennecke J, Hipfner DR, Stark A, Russell RB, Cohen SM. bantam encodes a developmentally regulated microRNA that controls cell proliferation and regulates the proapoptotic gene hid in Drosophila. Cell. 2003;113(1):25-36. doi:10.1016/s0092-8674(03)00231-9

11. Bryant B, Macdonald W, Raikhel AS. microRNA miR-275 is indispensable for blood digestion and egg development in the mosquito Aedes aegypti. Proc Natl Acad Sci U S A. 2010;107(52):22391-22398. doi:10.1073/pnas.1016230107 
12. Chomczynski P, Mackey K. Short technical reports. Modification of the TRI reagent procedure for isolation of RNA from polysaccharide- and proteoglycan-rich sources. Biotechniques. 1995;19(6):942-945.

13. de Miranda, J.R. et al. (2013) Standard methods for virus research in Apis mellifera. J. Apicult. Res. $52,1-56$

14. de Miranda JR, Genersch E. Deformed wing virus. J Invertebr Pathol. 2010;103 Suppl 1:S48-S61. doi:10.1016/j.jip.2009.06.01

15. Dennison NJ, BenMarzouk-Hidalgo OJ, Dimopoulos G. MicroRNA-regulation of Anopheles gambiae immunity to Plasmodium falciparum infection and midgut microbiota. Dev Comp Immunol. 2015;49(1):170-178. doi:10.1016/j.dci.2014.10.016

16. Di Prisco G, Annoscia D, Margiotta M, Ferrara R, Varricchio P, Zanni V, Caprio E, Nazzi F, Pennacchio F.Proc Natl Acad Sci U S A. 2016 Mar 22;113(12):3203-8. doi: 10.1073/pnas.1523515113

17. Feng X, Zhou S, Wang J, Hu W (2018) microRNA profiles and functions in mosquitoes. PLOS Neglected Tropical Diseases 12(5): e0006463. https://doi.org/10.1371/journal.pntd.0006463

18. Filipowicz W, Bhattacharyya SN, Sonenberg N. Mechanisms of post-transcriptional regulation by microRNAs: are the answers in sight? Nat Rev Genet. 2008;9(2):102-114. doi:10.1038/nrg2290

19. Fonseca PLC, Mucherino JJ, Porto JAM, Aemache JN, de Almeida JPP, de Silva FF, Olmo RP, Faria IJS, de Carvalho DS, Goes-Neto A, Correa RX, Oirovani CP, Pacheco LGC, Costa MA, Aguiar ERGR. (2021). Genome-wide identification of miRNAs and target regulatory newtwork in the invasive ectoparasitic mite Varroa destructor. Genomics 113:2290-23-3. https://doi.org/10.1016/j.ygeno.2021.05.028

20. Franceschini A, Szklarczyk D, Frankild S, Kuhn M, Simonovic M, Roth A, Lin J, Minguez P, Bork P, von Mering C, et al. 2013. STRING v9.1: protein-protein interaction networks, with increased coverage and integration. Nucleic Acids Res 41: D808-D815.

21. Friedländer MR, Mackowiak SD, Li N, Chen W, Rajewsky N. miRDeep2 accurately identifies known and hundreds of novel microRNA genes in seven animal clades. Nucleic Acids Res. 2012;40(1):37-52. doi:10.1093/nar/gkr688

22. Kulhanek K, Steinhauer N, Wilkes J, Wilson M, Spivak M, Sagili RR, Tarpy DR, McDermott E, Garavito A, Rennich K, vanEngelsdorp D. Survey-derived best management practices for backyard beekeepers improve colony health and reduce mortality. PLoS One. 2021 Jan 15;16(1):e0245490. doi: 10.1371/journal.pone.0245490.

23. Gisder S, Möckel N, Eisenhardt D, Genersch E. In vivo evolution of viral virulence: switching of deformed wing virus between hosts results in virulence changes and sequence shifts. Environ Microbiol. 2018;20(12):4612-4628. doi:10.1111/1462-2920.14481

24. Gisder $S$, Aumeier P, Genersch E. Deformed wing virus: replication and viral load in mites (Varroa destructor). J Gen Virol. 2009;90(Pt 2):463-467. doi:10.1099/vir.0.005579-0

25. Gallai N, Salles JM, Settele J, Vaissière BE. Economic valuation of the vulnerability of world agriculture confronted with pollinator decline. Ecol. Econ., 68 (3) (2009), pp. 810-821 
26. Goulson D, Nicholls E, Botías C, Rotheray EL. Bee declines driven by combined stress from parasites, pesticides, and lack of flowers. Science, 347 (6229) (2015), p. 1255957

27. Gregorc A, Alburaki M, Sampson B, Knight PR, Adamczyk J. Toxicity of Selected Acaricides to Honey Bees (Apis mellifera) and Varroa (Varroa destructor Anderson and Trueman) and Their Use in Controlling Varroa within Honey Bee Colonies. Insects. 2018;9(2):55. Published 2018 May 10. doi:10.3390/insects9020055

28. Gusachenko ON, Woodford L, Balbirnie-Cumming K, Ryabov EV, Evans DJ. Evidence for and against deformed wing virus spillover from honey bees to bumble bees: a reverse genetic analysis. Sci Rep. 2020;10(1):16847. Published 2020 Oct 8. doi:10.1038/s41598-020-73809-3

29. He Y, Lin J, Kong D, et al. Current State of Circulating MicroRNAs as Cancer Biomarkers. Clin Chem. 2015;61(9):1138-1155. doi:10.1373/clinchem.2015.241190

30. Higes, M., Martín-Hernández, R., Hernández-Rodríguez, C.S. et al. Assessing the resistance to acaricides in Varroa destructor from several Spanish locations. Parasitol Res 119, 3595-3601 (2020). https://doi.org/10.1007/s00436-020-06879-x

31. Highfield AC, El Nagar A, Mackinder L.C., et al. Deformed wing virus implicated in overwintering honeybee colony losses. Appl Environ Microbiol. 2009;75(22):7212-7220. doi:10.1128/AEM.0222709

32. Hristov P, Shumkova R, Palova N, Neov B. Factors Associated with Honey Bee Colony Losses: A MiniReview. Vet Sci. 2020;7(4):166. Published 2020 Oct 30. doi:10.3390/vetsci7040166

33. Hu W, Criscione F, Liang S, Tu Z. MicroRNAs of two medically important mosquito species: Aedes aegypti and Anopheles stephensi. Insect Mol Biol. 2015;24(2):240-252. doi:10.1111/imb.12152

34. Hung KJ, Kingston JM, Albrecht M, Holway DA, Kohn JR. The worldwide importance of honey bees as pollinators in natural habitats. Proc Biol Sci. 2018 Jan 10;285(1870):20172140. doi: 10.1098/rspb.2017.2140.

35. Hussain M, Walker T, O'Neill SL, Asgari S. Blood meal induced microRNA regulates development and immune associated genes in the Dengue mosquito vector, Aedes aegypti. Insect Biochem Mol Biol. 2013;43(2):146-152. doi:10.1016/j.ibmb.2012.11.005

36. Iqbal J, Mueller U.Proc Biol Sci. 2007 Jun 22;274(1617):1517-21. doi: 10.1098/rspb.2007.0022.

37. Jin H, Kim VN, Hyun S. Conserved microRNA miR-8 controls body size in response to steroid signaling in Drosophila. Genes Dev. 2012;26(13):1427-1432. doi:10.1101/gad.192872.112

38. John B, Enright AJ, Aravin A, Tuschl T, Sander C, Marks DS. 2004. Human MicroRNA targets. PLoS Biol 2: e363.

39. Kadener S, Menet JS, Sugino K, et al. A role for microRNAs in the Drosophila circadian clock. Genes Dev. 2009;23(18):2179-2191. doi:10.1101/gad.1819509

40. Kertesz M, lovino N, Unnerstall U, Gaul U, Segal E. 2007. The role of site accessibility in microRNA target recognition. Nat Genet 39: 1278-1284. 
41. Kloosterman WP, Plasterk RHA. (2006). The diverse functions of microRNAs in animal development and disease. Dev. Cell 11: 441-450. https://doi.org/10.1016/j.devcel.2006.09.009

42. Koleoglu G, Goodwin PH, Reyes-Quintana M, Hamiduzzaman MM, Guzman-Novoa E.Parasitol Res. 2018 Apr;117(4):1175-1183. doi: 10.1007/s00436-018-5796-8. Epub 2018 Feb 12.

43. Koleoglu G, Goodwin PH, Reyes-Quintana M, Hamiduzzaman MM, Guzman-Novoa E.PLoS One. 2017 Jan 12;12(1):e0169669. doi: 10.1371/journal.pone.0169669. eCollection 2017.

44. Le Conte Y, Ellis M, Ritter W. Varroa mites and honey bee health: can Varroa explain part of the colony losses?. Apidologie. 2010;41(3):353-63.

45. Lei Z, Lv Y, Wang W, et al. MiR-278-3p regulates pyrethroid resistance in Culex pipiens pallens. Parasitol Res. 2015;114(2):699-706. doi:10.1007/s00436-014-4236-7

46. Li Y, Andrade J. DEApp: an interactive web interface for differential expression analysis of next generation sequence data. Source Code Biol Med. 2017;12:2. Published 2017 Feb 3. doi:10.1186/s13029-017-0063-4

47. Liu, Y., Zhou, Y., Wu, J. et al. The expression profile of Aedes albopictus miRNAs is altered by dengue virus serotype-2 infection. Cell Biosci 5, 16 (2015). https://doi.org/10.1186/s13578-015-0009-y

48. Lucas KJ, Roy S, Ha J, Gervaise AL, Kokoza VA, Raikhel AS. MicroRNA-8 targets the Wingless signaling pathway in the female mosquito fat body to regulate reproductive processes. Proc Natl Acad Sci U S A. 2015;112(5):1440-1445. doi:10.1073/pnas.1424408112

49. Lucas K, Raikhel AS. Insect microRNAs: biogenesis, expression profiling and biological functions. Insect Biochem Mol Biol. 2013;43(1):24-38. doi:10.1016/j.ibmb.2012.10.009

50. Luhur A, Chawla G, Sokol NS: MicroRNAs as components of systemic signaling pathways in Drosophila melanogaster. Curr Top Dev Biol 2013, 105:97-123.

51. Luo H, Guo W, Wang F, et al. miR-1291 targets mucin 1 inhibiting cell proliferation and invasion to promote cell apoptosis in esophageal squamous cell carcinoma. Oncol Rep. 2015;34(5):2665-2673. doi:10.3892/or.2015.4206

52. Maharaj PD, Widen SG, Huang J, Wood TG, Thangamani S. Discovery of mosquito saliva microRNAs during CHIKV infection. PLoS Neg/ Trop Dis. 2015;9(1):e0003386. Published 2015 Jan 22. doi:10.1371/journal.pntd.0003386

53. Martin SJ and Brettell L.E. (2019) Deformed wing virus in honey bees and other insects. Annu. Rev. Virol. 6, 49-69

54. Martin S., 1998.- A population model for the ectoparasitic mite Varroa jacobsoni in honey bee (Apis mellifera) colonies. Ecological Modelling 109: 267-281.

55. Millán-Leiva A, Marín Ó, Christmon K, vanEngelsdorp D, González-Cabrera J. Mutations associated with pyrethroid resistance in Varroa mite, a parasite of honey bees, are widespread across the United States. Pest Manag Sci. 2021;77(7):3241-3249. doi:10.1002/ps.6366

56. Min H, Yoon S. 2010. Got target? Computational methods for microRNA target prediction and their extension. Exp Mol Med 42:233-244. 
57. Moore J, Jironkin A, Chandler D, Burroughs N, Evans DJ, Ryabov EV. Recombinants between Deformed wing virus and Varroa destructor virus-1 may prevail in Varroa destructor-infested honeybee colonies. J Gen Virol. 2011;92(Pt 1):156-161. doi:10.1099/vir.0.025965-0

58. Mordecai GJ, Brettell LE, Martin SJ, Dixon D, Jones IM, Schroeder DC. Superinfection exclusion and the long-term survival of honey bees in Varroa-infested colonies. ISME J. 2016;10(5):1182-1191. doi:10.1038/ismej.2015.186

59. Natsopoulou ME, McMahon DP, Paxton RJ.Behav Ecol Sociobiol. 2016;70(7):1019-1031. doi: 10.1007/s00265-015-2019-

60. Noël A, Le Conte Y, Mondet F. Varroa destructor: how does it harm Apis mellifera honey bees and what can be done about it? Emerg Top Life Sci. 2020 Jul 2;4(1):45-57. doi: 10.1042/ETLS20190125.

61. Osei-Amo S, Hussain M, O'Neill SL, Asgari S. Wolbachia-induced aae-miR-12 miRNA negatively regulates the expression of MCT1 and MCM6 genes in Wolbachia-infected mosquito cell line. PLOS One. 2012;7(11):e50049. doi:10.1371/journal.pone.0050049

62. Pizzorno MC, Field K, Kobokovich AL, Martin PL, Gupta RA, Mammone R, Rovnyak D, Capaldi EA.Viruses. 2021 Feb 12;13(2):287. doi: 10.3390/v13020287.

63. Posada-Florez F, Childers AK, Heerman MC, et al. Deformed wing virus type A, a major honey bee pathogen, is vectored by the mite Varroa destructor in a non-propagative manner. Sci Rep. 2019;9(1):12445. Published 2019 Aug 27. doi:10.1038/s41598-019-47447-3

64. Quinlan AR, Hall IM. BEDTools: a flexible suite of utilities for comparing genomic features. Bioinformatics. 2010;26(6):841-842. doi:10.1093/bioinformatics/btq033

65. Ramsey SD, Ochoa R, Bauchan G, Gulbronson C, Mowery JD, Cohen A, Lim D, Joklik J, Cicero JM, Ellis JD, Hawthorne D, vanEngelsdorp D. Varroa destructor feeds primarily on honey bee fat body tissue and not hemolymph. Proc Natl Acad Sci U S A. 2019 Jan 29;116(5):1792-1801. doi: 10.1073/pnas.1818371116.

66. Remnant EJ, Mather N, Gillard TL, Yagound B, Beekman M. Direct transmission by injection affects competition among RNA viruses in honeybees. Proc Biol Sci. 2019;286(1895):20182452. doi:10.1098/rspb.2018.2452

67. Rinkevich FD. Detection of amitraz resistance and reduced treatment efficacy in the Varroa Mite, Varroa destructor, within commercial beekeeping operations. PLoS One. 2020;15(1):e0227264. Published 2020 Jan 17. doi:10.1371/journal.pone.0227264

68. Rosche KL, Sidak-Loftis LC, Hurtado J, Fisk EA, Shaw DK. Arthropods Under Pressure: Stress Responses and Immunity at the Pathogen-Vector Interface. Front Immunol. 2021;11:629777. Published 2021 Feb 15. doi:10.3389/fimmu.2020.629777

69. Ryabov EV, Childers AK, Lopez D, et al. Dynamic evolution in the key honey bee pathogen deformed wing virus: Novel insights into virulence and competition using reverse genetics. PLOS Biol. 2019;17(10):e3000502. Published 2019 Oct 10. doi:10.1371/journal.pbio.3000502

70. Saldaña, M. A., Etebari, K., Hart, C. E., Widen, S. G., Wood, T. G., Thangamani, S., Asgari, S., \& Hughes, G. L. (2017). Zika virus alters the microRNA expression profile and elicits an RNAi response in Aedes 
aegypti mosquitoes. PLoS neglected tropical diseases, 11(7), e0005760.

71. Sempere LF, Sokol NS, Dubrovsky EB, Berger EM, Ambros V. Temporal regulation of microRNA expression in Drosophila melanogaster mediated by hormonal signals and broad-Complex gene activity. Dev Biol. 2003;259(1):9-18. doi:10.1016/s0012-1606(03)00208-2

72. Sturm M, Hackenberg M, Langenberger D, Frishman D. 2010. TargetSpy: a supervised machine learning approach for microRNA target prediction. BMC Bioinformatics 11: 292.

73. Shao $\mathrm{H}$, Wang $\mathrm{H}$, Tang $\mathrm{X}$. NAC transcription factors in plant multiple abiotic stress responses: progress and prospects. Front Plant Sci. 2015;6:902. Published 2015 Oct 29. doi:10.3389/fpls.2015.00902

74. Techer MA, Rane RV, Grau ML, et al. Divergent evolutionary trajectories following speciation in two ectoparasitic honey bee mites. Commun Biol. 2019;2:357. Published 2019 Oct 1. doi:10.1038/s42003-019-0606-0

75. Toronen P, Medlar A, Holm, L. PANNZER2: a rapid functional annotation web server, Nucleic Acids Res. 46 (2018) W84-W88, https://doi.org/10.1093/nar/ gky350.

76. Traniello IM, Bukhari SA, Kevill J, Ahmed AC, Hamilton AR, Naeger NL, Schroeder DC, Robinson GE.Sci Rep. 2020 Feb 20;10(1):3101. doi: 10.1038/s41598-020-59808-4.

77. van Dooremalen C, Gerritsen L, Cornelissen B, van der Steen JJM, van Langevelde F, Blacquière T (2012) Winter Survival of Individual Honey Bees and Honey Bee Colonies Depends on Level of Varroa destructor Infestation. PLoS ONE 7(4): e36285. https://doi.org/10.1371/journal.pone.0036285

78. Wang $\mathrm{Y}$, Jiang $\mathrm{F}$, Wang $\mathrm{H}$, et al. Evidence for the expression of abundant microRNAs in the locust genome. Sci Rep. 2015;5:13608. Published 2015 Sep 2. doi:10.1038/srep13608

79. Wang Y, Gosselin Grenet AS, Castelli I, et al. Densovirus crosses the insect midgut by transcytosis and disturbs the epithelial barrier function. J Virol. 2013;87(22):12380-12391.

doi:10.1128/JVI.01396-13

80. Webster TC, Delaplane KS. 2001. Mites of the Honey Bee. Dadant and Sons, Inc., Hamilton, Illinois. $280 \mathrm{pp}$

81. Wells T, Wolf S, Nicholls E, Groll H, Lim KS, Clark SJ, Swain J, Osborne JL, Haughton AJ.Environ Microbiol Rep. 2016 Oct;8(5):728-737. doi: 10.1111/1758-2229.12434. Epub 2016 Jul 7.

82. Wilfert, et al. Deformed wing virus is a recent global epidemic in honey bees driven by Varroa mites. Science, 351 (2016), pp. 594-597

83. Winter F, Edaye S, Hüttenhofer A, Brunel C. Anopheles gambiae miRNAs as actors of defence reaction against Plasmodium invasion. Nucleic Acids Res. 2007;35(20):6953-6962. doi:10.1093/nar/gkm686

84. Xu MJ, Fu JH, Nisbet AJ, et al. Comparative profiling of microRNAs in male and female adults of Ascaris suum. Parasitol Res. 2013;112(3):1189-1195. doi:10.1007/s00436-012-3250-x

85. Yan H, Zhou Y, Liu Y, Deng Y, Chen X. miR-252 of the Asian tiger mosquito Aedes albopictus regulates dengue virus replication by suppressing the expression of the dengue virus envelope protein. $J$ Med Virol. 2014;86(8):1428-1436. doi:10.1002/jmv.23815 
86. Yang X, Cox-Foster DL. Impact of an ectoparasite on the immunity and pathology of an invertebrate: evidence for host immunosuppression and viral amplification. Proc Natl Acad Sci U S A. 2005;102(21):7470-7475. doi:10.1073/pnas.0501860102

87. Ye J, Zhang Y, Cui H, Liu J, Wu Y, Cheng Y, Xu H, Huang X, Li S, Zhou A, Zhang X, L. Bolund L, Q. Chen Q, J. Wang J, H. Yang L, Fang C, Shi C, WEGO 2.0: a web tool for analyzing and plotting G.O. annotations, 2018 update, Nucleic Acids Res. 46 (2018) (2021) W71-W75, https://doi.org/10.1093/nar/gky400

88. Zhou B, Ma R, Si W, et al. MicroRNA-503 targets FGF2 and VEGFA and inhibits tumor angiogenesis and growth. Cancer Lett. 2013;333(2):159-169. doi:10.1016/j.canlet.2013.01.028

\section{Figures}

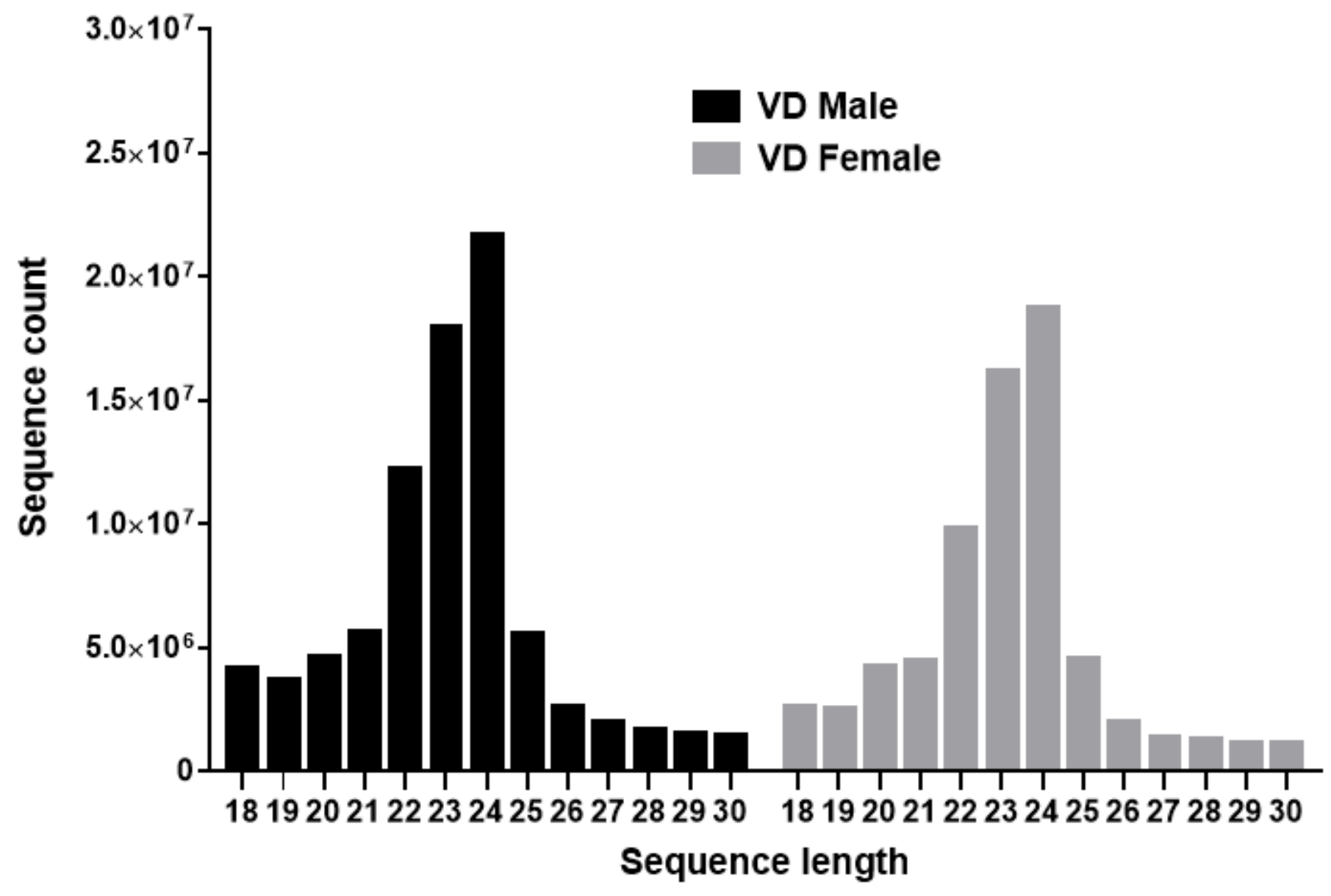

Figure 1

Small RNA Sequence length distribution of microRNAs in male and female Varroa destructor (VD) mites. The length of microRNA is twenty-four (24) nucleotides. 


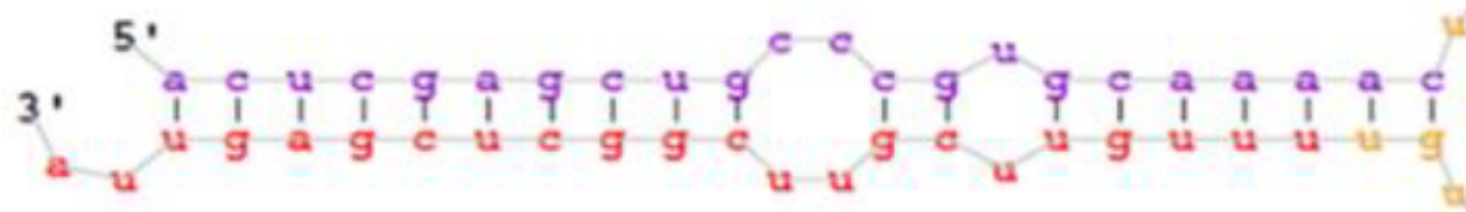

\begin{tabular}{|l|c|}
\hline Provisional ID & nDSW_002860020.1_1808 \\
\hline Score total & 485654.1 \\
\hline Score for star read(s) & 3.9 \\
\hline Score for read counts & 485643.7 \\
\hline Score for mfe & 1.8 \\
\hline Score for randfold & 1.6 \\
\hline Score for cons. Seed & 3 \\
\hline Total read count & 952581 \\
\hline Mature read count & 949093 \\
\hline Loop read count & 15 \\
\hline Star read count & 3488 \\
\hline
\end{tabular}

\section{B}

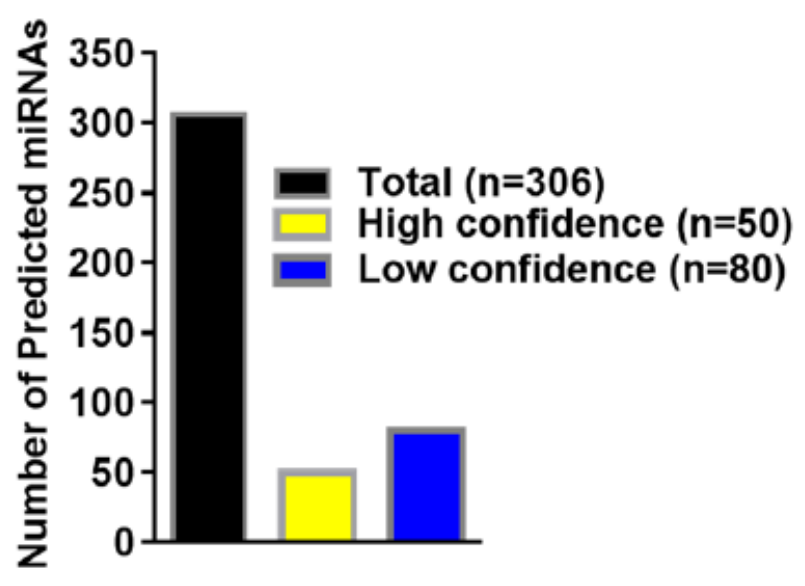

Figure 2

A. Basic stem-loop structures of predicted microRNAs. miRDeep2 software was used to identify potential miRNA precursors based on nucleotide length, star sequence, stem-loop folding, and homology to the Varroa reference genome. It shows the predicted stem-loop structures, star, and mature sequences of predicted miRNA in Varroa mite. B. Annotation of predicted Varroa destructor microRNAs. 306 microRNAs 
were predicted in varroa samples. 50 of them were categorized as high confidence $(n=\sim 50)$, low confidence ( 80) miRNAs based on the standard criteria

A

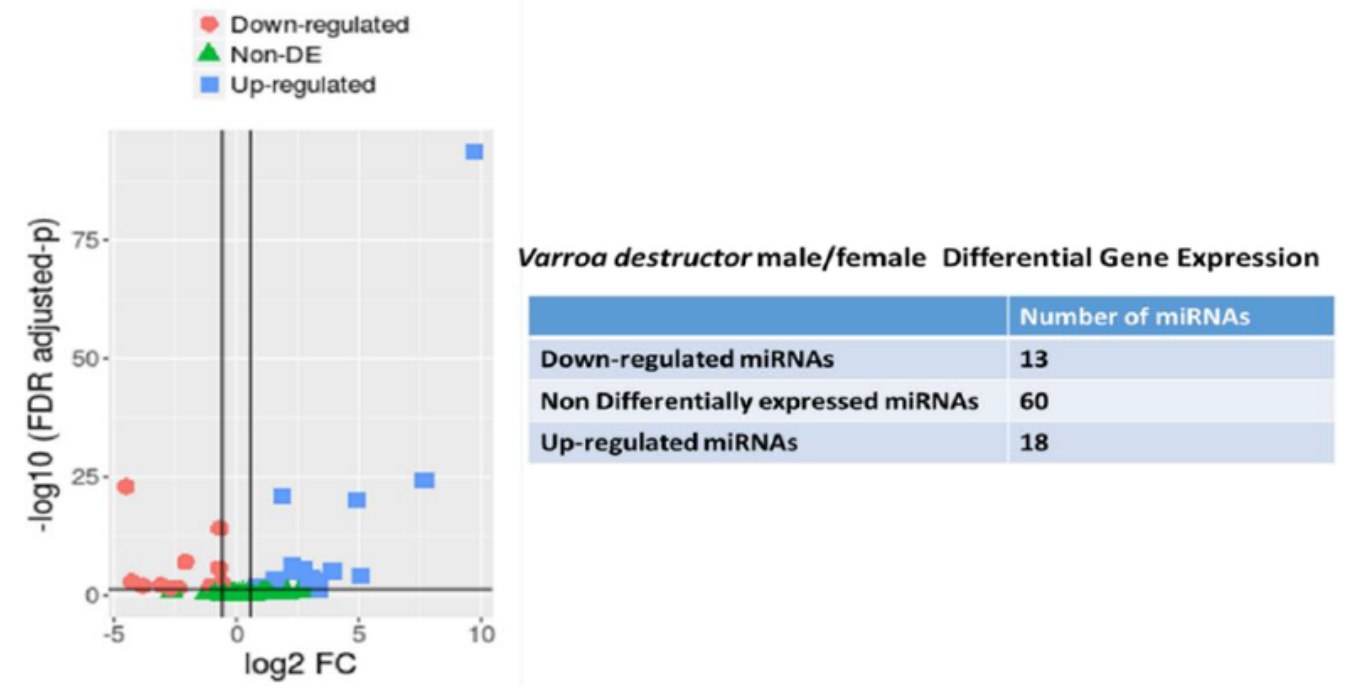

B

9

6

Upregulated miRNAs

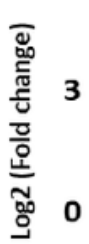

$-3$

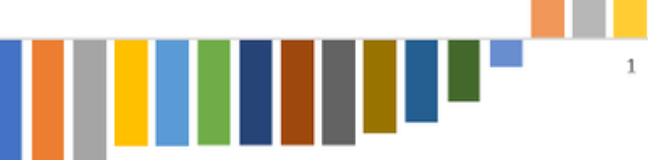

Downregulated miRNAs

$-6$

= vde-miR-1002-5p

nDS_019211458.1_34062

nDS_019211454.1_3258

nDS_019211454.1_7299

vine-miR-958-3p

vide-bantam-3p

$=$ vde-miR-4943-3p

Eve vde-miR-87-3p

nDS_019211459.1_37129

novel:NW_019211454.1_5540

n nDS_019211456.1_17707

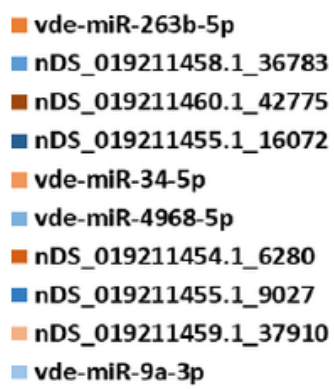

= vde-miR-9a-3p

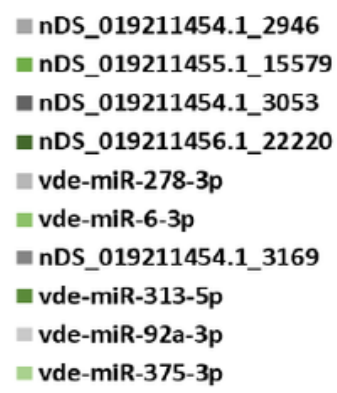

\section{Figure 3}

A. In silico differential expression of predicted microRNAs in female Varroa destructor relative to males. EdgeR was used for differential expression analysis. 13 predicted microRNAs were down-regulated, 18 upregulated, while 60 were unaffected. B. Differential expression of individual microRNAs in Varroa 
females relative to males. miRNAs with a Log2 fold-change expression $>|1|$ and FDR $\leq 0.1$ were considered significantly differentially expressed with respect to male microRNAs (Refer Table1).

A

\begin{tabular}{|l|l|}
\hline Dm homologs & Role of microRNA (from literature) \\
\hline dme-miR-278-3p & Insecticide pyrethroid resistance \\
\hline dme-miR-6-3p & Metamorphosis \\
\hline dme-miR-9a-3p & In developmental stages \\
\hline dme-miR-375-3p & $\begin{array}{l}\text { Dengue virus (DENV) replication in } \\
\text { mosquitoes }\end{array}$ \\
\hline dme-miR-34-5p & $\begin{array}{l}\text { Immune response during DENV-2 } \\
\text { infection }\end{array}$ \\
\hline dme-miR-252-5p & Inhibits DENV replication \\
\hline dme-bantam-3p & $\begin{array}{l}\text { Proliferation, development, apoptosis, } \\
\text { CHIKV infection }\end{array}$ \\
\hline dme-miR-8-3p & A. aegypti reproduction \\
\hline dme-miR-87-3p & $\begin{array}{l}\text { Metamorphosis, Immune response } \\
\text { during DENV-2 infection }\end{array}$ \\
\hline
\end{tabular}

B

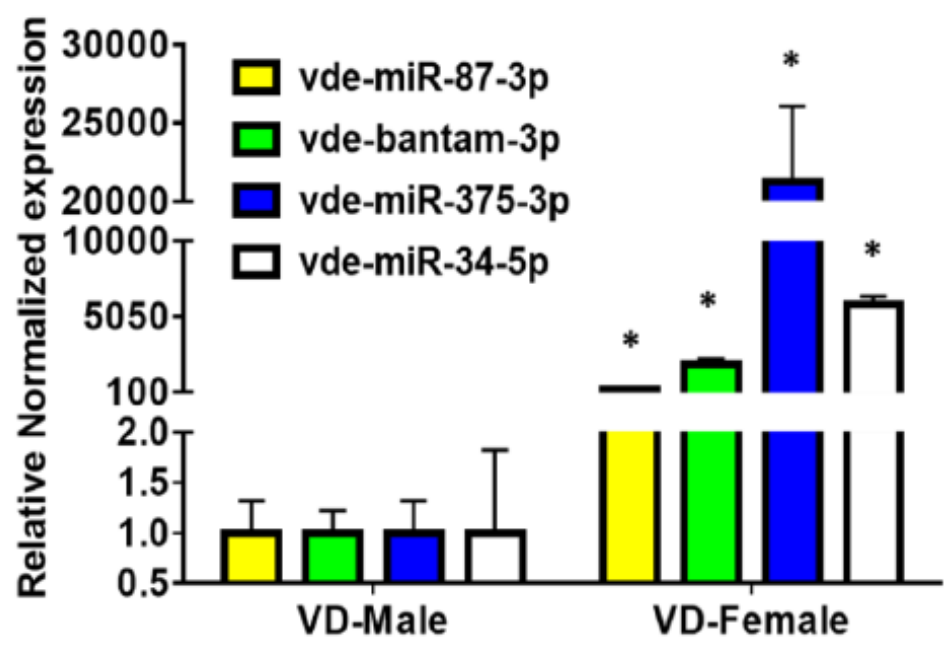

\section{Figure 4}

A. MicroRNA candidates predicted in this study, conserved in other arthropods also and based on available literature, play significant role in replication, harboring and inhibition of viral pathogens. B. qRTPCR expression of potential microRNAs found in the present study in DWV-B infected male and female varroa mites. Succinate dehydrogenase (SDHA) was used as the house-keeping gene for normalization. Expression of these microRNAs is comparatively higher in female than male Varroa.

\begin{tabular}{|l|r|r|r|l|r|r|}
\hline $\begin{array}{l}\text { \% abundance of various small } \\
\text { RNAs }\end{array}$ & miRNA & rRNA & tRNA & snRNA & snoRNA & Others \\
\hline Female Varroa mite & 0.0056 & 0.15 & 0.5 & 0.0013 & 0.00029 & 99.35 \\
\hline Male Varroa mite & 0.0025 & 0.015 & 0.094 & 0.0004 & $2.35 \mathrm{E}-05$ & 99.89 \\
\hline
\end{tabular}

A

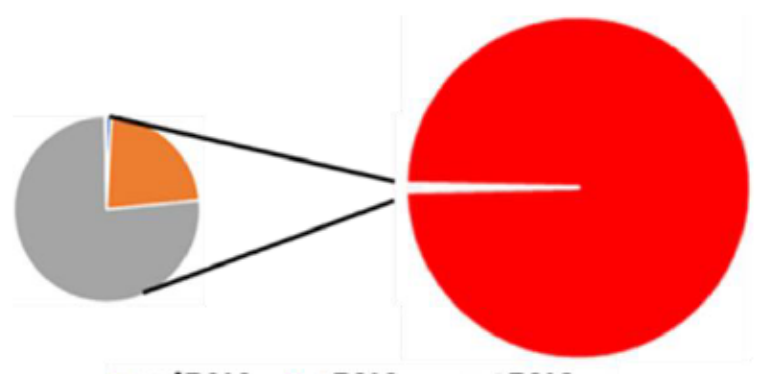

$=$ miRNA $=$ rRNA $=$ tRNA

snRNA $=$ snoRNA $=$ Others
B

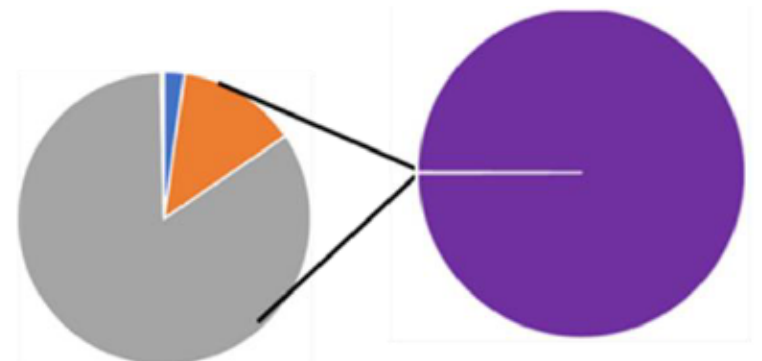

miRNA
rRNA
snRNA $=$ snoRNA $=$ Others 
Figure 5

Summary of the Varroa derived female (A) and male (B) small RNA reads that match various small RNA categories.

A

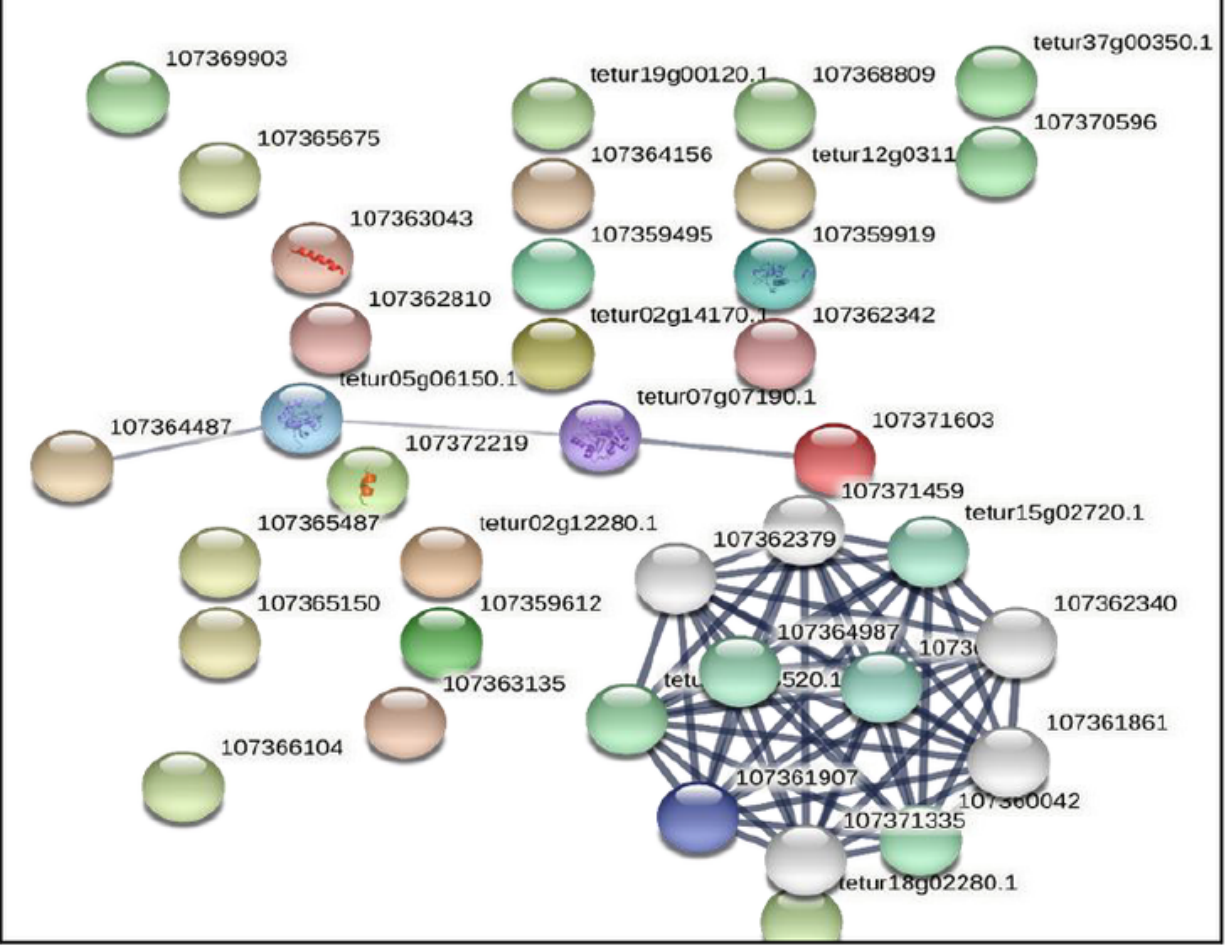

B

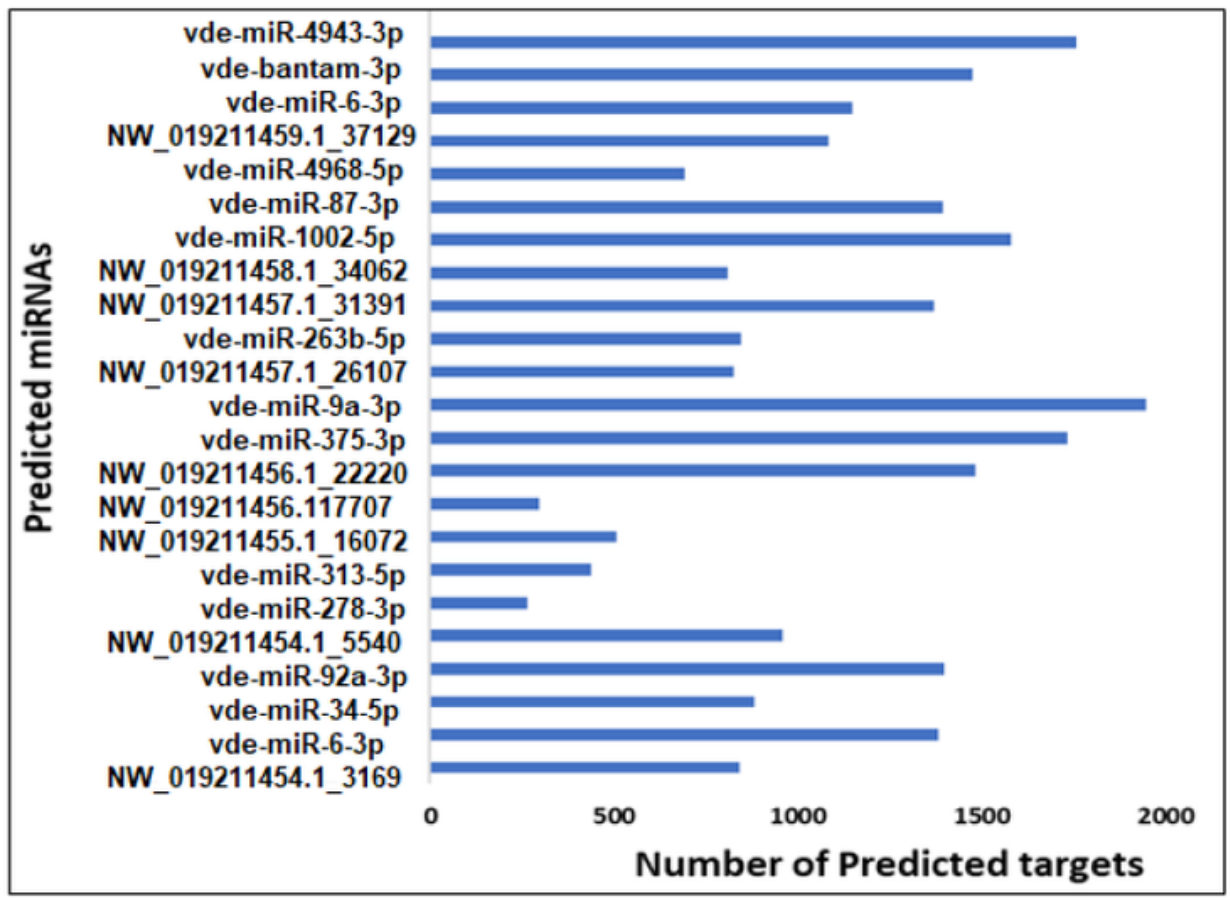

Figure 6 
(A) A network built exclusively from Varroa proteins targeted by predicted upregulated/downregulated miRNAs. (B) The total number of predicted target transcripts significantly upregulated and downregulated in female Varroa miRNAs relative to male miRNAs.

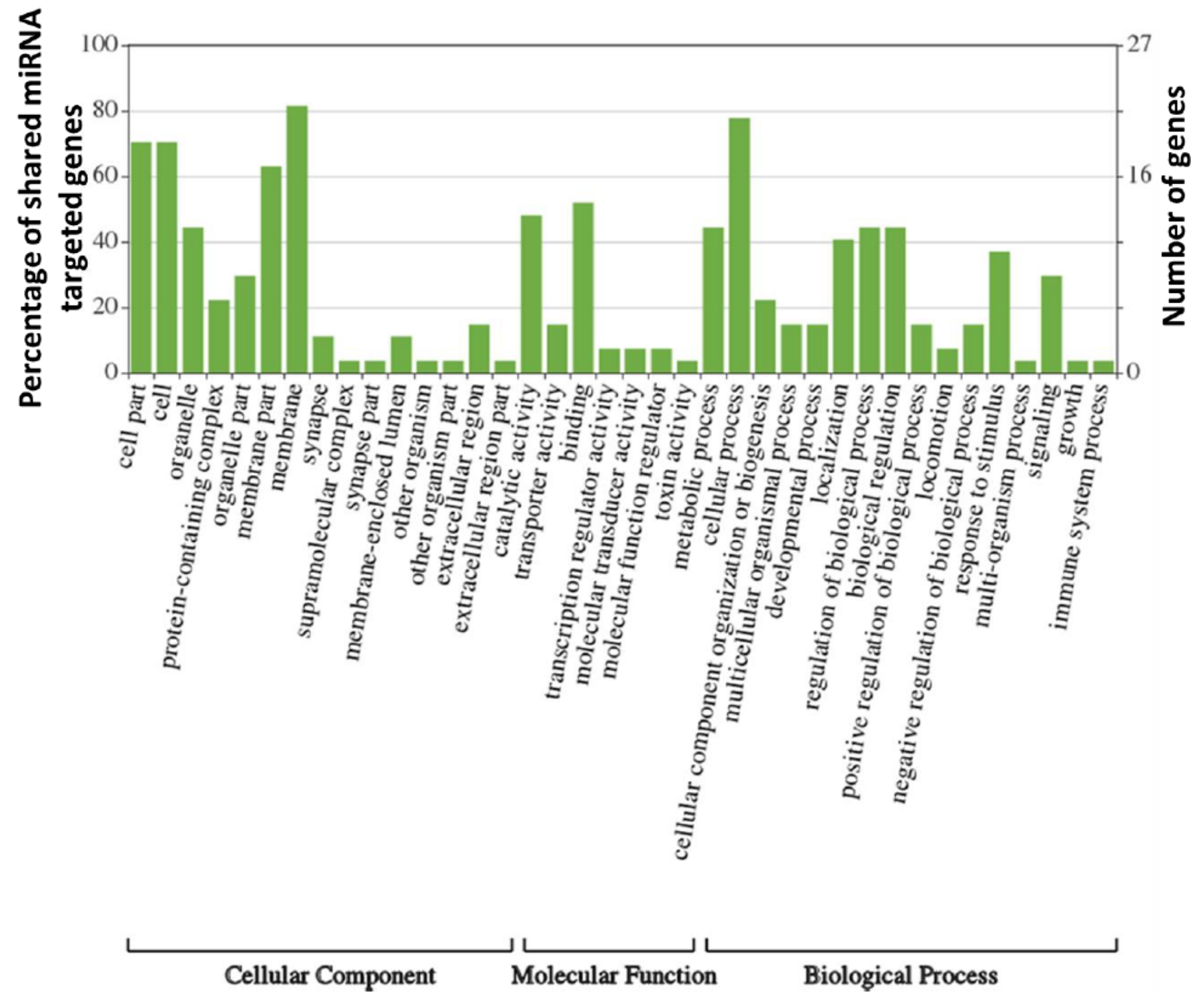

Figure 7

Gene ontology (GO) derived biological processes related to genes targeted by upregulated/downregulated miRNAs in female $\mathrm{V}$. destructor. 


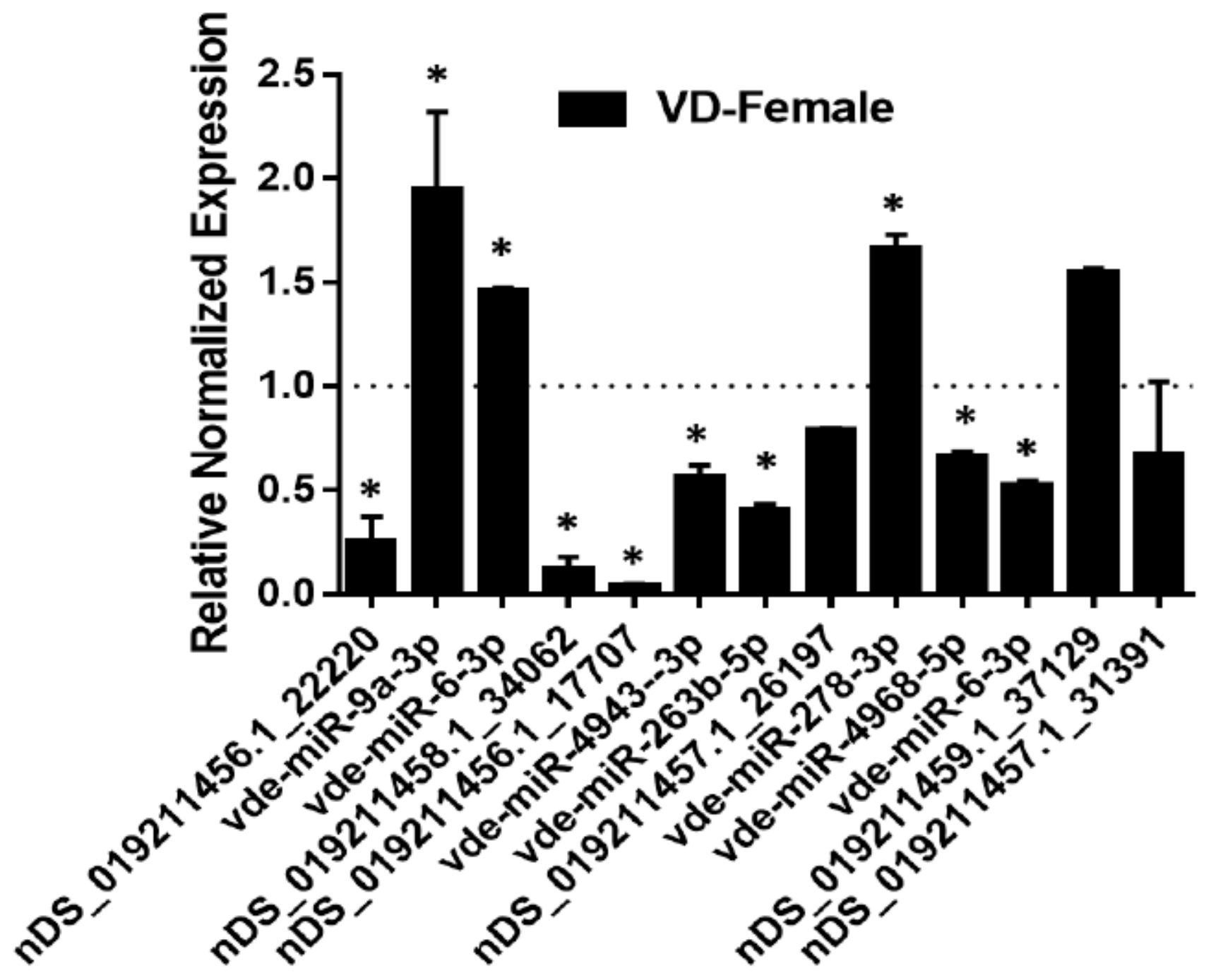

Figure 8

qPCR validation of selected mature miRNAs (High confidence) of female Varroa that are differentially expressed relative to male Varroa. Statistical signifcance for qRT-PCR-based differential expression was determined by the 2-tailed Student' 's t-test where * is $p<0.05$.

\section{Supplementary Files}

This is a list of supplementary files associated with this preprint. Click to download.

- Supplementarydata.docx 